\title{
Next-generation sequencing for hypothesis- free genomic detection of invasive tropical infections in poly-microbially contaminated, formalin-fixed, paraffin-embedded tissue samples - a proof-of-principle assessment
}

\author{
Hagen Frickmann ${ }^{1,2^{*}}$ (D), Carsten Künne ${ }^{3}$, Ralf Matthias Hagen ${ }^{4}$, Andreas Podbielski $^{2}$, Jana Normann ${ }^{2}$,
} Sven Poppert ${ }^{5,6}$, Mario Looso ${ }^{3}$ and Bernd Kreikemeyer ${ }^{2}$

\begin{abstract}
Background: The potential of next-generation sequencing (NGS) for hypothesis-free pathogen diagnosis from (poly-)microbially contaminated, formalin-fixed, paraffin embedded tissue samples from patients with invasive fungal infections and amebiasis was investigated. Samples from patients with chromoblastomycosis $(n=3)$, coccidioidomycosis $(n=2)$, histoplasmosis $(n=4)$, histoplasmosis or cryptococcosis with poor histological discriminability $(n=1)$, mucormycosis $(n=2)$, mycetoma $(n=3)$, rhinosporidiosis $(n=2)$, and invasive Entamoeba histolytica infections $(n=$ 6) were analyzed by NGS (each one Illumina v3 run per sample). To discriminate contamination from putative infections in NGS analysis, mean and standard deviation of the number of specific sequence fragments (paired reads) were determined and compared in all samples examined for the pathogens in question.

Results: For matches between NGS results and histological diagnoses, a percentage of species-specific reads greater than the 4th standard deviation above the mean value of all 23 assessed sample materials was required. Potentially etiologically relevant pathogens could be identified by NGS in 5 out of 17 samples of patients with invasive mycoses and in 1 out of 6 samples of patients with amebiasis.
\end{abstract}

Conclusions: The use of NGS for hypothesis-free pathogen diagnosis from contamination-prone formalinfixed, paraffin-embedded tissue requires further standardization.

Keywords: NGS, Next-generation sequencing, Hypothesis-free diagnosis of infection, Invasive fungal infections, Invasive amebiasis, FFPE, formalin-fixed, paraffin-embedded samples, Molecular diagnostics, Tropical infectious diseases, Metagenome

\section{Background}

Reliable results of microbiological diagnostic approaches, in particular of cultural approaches, require suitable pre-analytical conditions as a prerequisite [1]. The intentional or unintentional inactivation of infectious agents can complicate diagnostic procedures. This is the

\footnotetext{
* Correspondence: Frickmann@bnitm.de

'Department of Microbiology and Hospital Hygiene, Bundeswehr Hospital

Hamburg, Bernhard-Nocht Str. 74, 20359 Hamburg, Germany

${ }^{2}$ Institute for Microbiology, Virology and Hygiene, University Medicine

Rostock, Schillingallee 70, 18057 Rostock, Germany

Full list of author information is available at the end of the article
}

case, for example, when the possibility of infection is not taken into account during initial sampling, so that the sample material is fixed for histopathological work-up in $4 \%$ buffered formalin for the purpose of preservation of tissue structure and subsequently embedded in paraffin in the pathology laboratory. If histology provides evidence of an infectious cause for an inflammatory reaction, cultural diagnostic approaches are no longer possible because of inactivation of microorganisms by formalin.

(c) The Author(s). 2019 Open Access This article is distributed under the terms of the Creative Commons Attribution 4.0 International License (http://creativecommons.org/licenses/by/4.0/), which permits unrestricted use, distribution, and 
The sensitivity of molecular diagnostic methods, for example, of polymerase chain reaction (PCR), is significantly reduced by formalin due to nucleic acid and protein cross-linking, deamination of cytosine to uracil, strand breaks, and the difficulty of extracting DNA from paraffin-embedded tissues [2-7]. If the microscopic detection of pathogens proves inconclusive, the molecular detection of pathogens from formalin-fixed sample material is nevertheless the most promising approach if fresh sample material cannot be obtained or can only be obtained with a significant health risk for the patient [7].

The sensitivity of molecular pathogen detection from formalin-fixed, paraffin-embedded (FFPE) tissue is influenced by factors such as sample age and pathogen density [7]. Best results can be expected for PCRs that amplify very short fragments, since the formalin-induced strand breaks, cross-linking of DNA strands, and protein-DNA cross-links prevent the amplification of larger fragments. Such cross-linking events are-stochastically-expected about every 1000 base pairs and reduce the reliability of PCRs with longer amplicons. This is especially true if samples inherently include only small quantities of pathogen DNA [7].

A limitation of targeted PCR diagnostics is the fact that primer-based nucleic acid amplification detects nucleic acids of defined pathogens or groups of pathogens only. If symptoms of the patient are nonspecific and can be induced by a variety of potential pathogens, rational selection of applicable PCR panels that are both comprehensive and economical can represent a differential diagnostic challenge [8].

Pan-bacterial or pan-fungal ribosomal RNA gene PCRs with subsequent Sanger sequencing [9] for the sequence-based identification of bacteria and fungi in the sample material [10] are potential alternatives to genusor species-specific PCR. These procedures are poorly standardized and therefore-especially in case of a negative result-doubtful in their diagnostic reliability [10], although they can provide valuable information in case of a positive result. There is complementary diagnostic value of this method mainly for sterile sample materials obtained from primary sterile compartments; for example, bioptic material of endocarditis patients [11]. In mixed cultures or samples with poly-microbial contamination, mixed sequences occur in Sanger sequencing that do not allow reliable pathogen identification [12]. However, such microbial contamination has to be regularly expected in formalin-fixed, paraffin-embedded sample material due to nonsterile storage of the paraffin blocks or contamination in the paraffin wax itself [13]. Consequently, the diagnostic value of such procedures is limited for FFPE materials.

The diagnostic application of NGS (next-generation sequencing) from primary material is a potential alternative. Hypothesis-free NGS has been used to successfully attribute etiologically unclear infection events to specific pathogens [14]. However, NGS is also suitable for the assessment of primary nonsterile sample materials. The assignment of etiological relevance with respect to the existing clinical symptoms can be based upon the relative frequency of pathogen-specific nucleic acid sequences [15] or on the pathogenicity of molecularly proven microorganisms. An example is the diagnosis of ornithosis by NGS-based demonstration of C. psittaci DNA in respiratory secretions of patients with severe respiratory infection of unknown origin [16].

The application of NGS with FFPE sample materials in general [17] and the purpose of pathogen detection and typing from such materials in particular [18] are the subjects of ongoing evaluation studies. The present study deals with NGS-based detection of invasive, mostly tropical, mycoses and invasive amebiasis from histological specimens. Matching between NGS and specific PCR for E. histolytica or panfungal PCR with subsequent Sanger sequencing as well as potential additional information on relevant etiologic pathogens provided by NGS are assessed.

The hypothesis of the study is that NGS may be more suitable for the hypothesis-free genomic detection of rare invasive infections in potentially poly-microbially contaminated, formalin-fixed, paraffin-embedded tissue samples than PCR with subsequent Sanger sequencing. The advantage of NGS is its suitability for parallel sequencing of virtually all DNA sequences within a biological sample, depending only on the depth of sequencing. If, in contrast, PCR primers with specificity for multiple pathogens, such as pan-fungal primers, lead to amplification of sequences of different pathogens within the same sample, overlays of different sequences can lead to non-interpretable results in Sanger sequencing.

\section{Results}

\section{Results of the NGS analyses}

The number of evaluable sequence fragments (reads) per sample averaged 9,799,803 $\pm 6,662,643$ (standard deviation) (lowest number 2,717,953 reads; highest number $29,225,435$ reads) in the NGS examination. Among these reads, an average of $26 \% \pm 19 \%$ (lowest percentage 1\%; highest percentage 59\%) could not be identified by the Kraken software.

No significant Spearman rank correlation between sample age and number of detected reads could be identified with Spearman $r=0.2962$ (corrected for ties), a 95\% confidence interval of -0.1449 to 0.6391 , and a non-significant two-tailed $P=0.1699$ (calculated using the software GraphPad InStat, version 3.06, 32 bit for Windows, GraphPad Software Inc., San Diego, CA, USA). 
The proportion of sequences of eukaryotic organisms in the sample averaged $39.7 \% \pm 36.7 \%$. The largest share consisted of human reads at $37.6 \% \pm 37.2 \%$. The proportion of fungal sequences was a mere $0.12 \% \pm 0.16 \%$. Bacterial sequences constituted an average of $23.9 \% \pm 22.0 \%$, viral sequences an average of $10.5 \% \pm 7.2 \%$. The identified sequences covered a wide spectrum of different species without clear relation to the histologically defined invasive infections. Among the bacterial sequences, Pseudomonas spp.-specific reads constituted $0.6 \% \pm 0.6 \%$ of all reads, and Staphylococcus spp.-specific reads $0.01 \% \pm 0.02 \%$ of all reads. Although some of the patients with invasive fungal infections had suffered from AIDS (personal communication with the Department of Pathology of the Bernhard Nocht Institute for Tropical Medicine Hamburg, which initially provided the samples), proviral DNA of HIV was undetectable in any of the samples.

The distribution of detectable reads is visualized in Table 1.

Focusing on the proven fungal sequences in the samples of the patients with invasive fungal infections, etiologically relevant pathogens, i.e. Histoplasma capsulatum, Madurella mycetomatis, and Fusarium pseudograminearum, matching the histological diagnosis were detected in 3 out of 17 samples among the three most frequently detected fungal species. Among these, there were two cases of histoplasmosis and mycetoma that were also confirmed by pan-fungal PCR [13] (see below). Specifically, Histoplasma capsulatum sequences constituted the most frequent fungal reads in the histoplasmosis sample. In detail, the corresponding reads were $0.02 \%$ of total reads in the sample and $34 \%$ of fungal reads. Madurella mycetomatis-specific sequences amounted to $0.001 \%$ of total reads in the respective sample and $4 \%$ of fungal reads, corresponding to position 3 of the most frequently detected fungal sequences in the mycetoma sample. In another mycetoma sample, a Fusarium species, here Fusarium pseudograminearum, was on position 2 of the most frequently detected fungi with $0.02 \%$ of total reads in the sample and $16 \%$ of fungal reads. In all other samples studied, spores of fungi from the environment were on positions 1 to 3 of the most frequently detectable fungal reads. The frequently detected

Table 1 Detectable reads per sample and distribution by kingdom

\begin{tabular}{|c|c|c|c|c|c|c|c|c|c|}
\hline Sample & Histological diagnosis & $\begin{array}{l}\text { Total read } \\
\text { pairs }\end{array}$ & $\begin{array}{l}\text { Assigned read } \\
\text { pairs }\end{array}$ & $\begin{array}{l}\text { Unassigned read } \\
\text { pairs }\end{array}$ & $\begin{array}{l}\text { Eukaryotes } \\
\text { excluding fungi }\end{array}$ & Fungi & Bacteria & Viruses & Archaea \\
\hline 1 & Chromoblastomycosis & $3,937,419$ & $1,147,985$ & $2,789,434$ & 21,600 & 2046 & 478,980 & 645,351 & 8 \\
\hline 2 & Mucormycosis & $9,624,603$ & $3,993,184$ & $5,631,419$ & $1,826,409$ & 4829 & $1,103,678$ & $1,058,228$ & 40 \\
\hline 3 & Histoplasmosis & $10,377,343$ & $9,642,335$ & 735,008 & $8,649,198$ & 1015 & 138,392 & 853,722 & 8 \\
\hline 4 & Mucormycosis & $2,717,953$ & $1,219,660$ & $1,498,293$ & 237,965 & 850 & 261,919 & 718,923 & 3 \\
\hline 5 & $\begin{array}{l}\text { Histoplasmosis or } \\
\text { cryptococcosis }\end{array}$ & $6,697,156$ & $2,829,244$ & $3,867,912$ & 841,420 & 3087 & $1,484,221$ & 500,489 & 27 \\
\hline 6 & Chromoblastomycosis & $6,986,916$ & $5,321,271$ & $1,665,645$ & 416,898 & 995 & $3,399,811$ & $1,503,362$ & 205 \\
\hline 7 & Rhinosporidiosis & $4,437,770$ & $1,742,087$ & $2,695,683$ & 215,943 & 3209 & 826,178 & 696,741 & 16 \\
\hline 8 & Mycetoma & $2,729,331$ & $1,935,487$ & 793,844 & $1,153,381$ & 1661 & 125,046 & 655,398 & 1 \\
\hline 9 & Rhinosporidiosis & $6,383,726$ & $1,568,557$ & $4,815,169$ & 28,812 & 3579 & 906,363 & 629,763 & 40 \\
\hline 10 & Mycetoma & $5,596,933$ & $2,098,943$ & $3,497,990$ & 901,105 & 3678 & 627,175 & 566,972 & 13 \\
\hline 11 & Histoplasmosis & $7,109,960$ & $5,690,358$ & $1,419,602$ & $1,145,879$ & 16,632 & $3,252,319$ & $1,275,523$ & 5 \\
\hline 12 & Histoplasmosis & $3,083,524$ & $1,148,615$ & $1,934,909$ & 205,871 & 6699 & 408,619 & 527,415 & 11 \\
\hline 13 & Chromoblastomycosis & $12,529,855$ & $6,557,056$ & $5,972,799$ & $4,427,985$ & 8699 & $1,055,351$ & $1,064,979$ & 42 \\
\hline 14 & Histoplasmosis & $7,901,861$ & $6,886,130$ & 1015,731 & $5,895,735$ & 2171 & 413,407 & 574,811 & 6 \\
\hline 15 & Coccidioidomycosis & $7,570,025$ & $2,732,014$ & $4,838,011$ & 359,079 & 9784 & $1,757,949$ & 605,165 & 37 \\
\hline 16 & Coccidioidomycosis & $8,791,653$ & $7,216,906$ & $1,574,747$ & $4,307,983$ & 1696 & $2,422,677$ & 484,421 & 129 \\
\hline 17 & Mycetoma & $9,178,967$ & $7,682,742$ & $1,496,225$ & $6,872,406$ & 1116 & 237,152 & 572,064 & 4 \\
\hline 18 & Invasive amebiasis & $16,947,754$ & $15,543,806$ & $1,403,948$ & 583,362 & 561 & $13,508,300$ & $1,447,733$ & 3850 \\
\hline 19 & Invasive amebiasis & $7,267,378$ & $6,313,385$ & 953,993 & $6,255,013$ & 1446 & 45,602 & 11,324 & 0 \\
\hline 20 & Invasive amebiasis & $22,840,836$ & $22,215,617$ & 625,219 & $21,555,613$ & 2401 & 151,650 & 505,953 & 0 \\
\hline 21 & Invasive amebiasis & $24,171,093$ & $22,848,176$ & $1,322,917$ & $22,100,882$ & 6631 & 193,348 & 547,309 & 6 \\
\hline 22 & Invasive amebiasis & $29,225,435$ & $28,785,110$ & 440,325 & $28,194,606$ & 1284 & 63,325 & 525,890 & 5 \\
\hline 23 & Invasive amebiasis & $15,262,467$ & $12,996,958$ & $2,265,509$ & $12,256,665$ & 5047 & 138,208 & 597,018 & 20 \\
\hline
\end{tabular}


environmental fungi comprised Auricularia delicata, Botrytis cinerea, Coniosporium apollinis, Debaryomyces hansenii var. Hansenii, Eutypa lata, Gaeumannomyces graminis, Malassezia globosa, Marssonina brunnea, Meyerozyma guilliermondii, Neofusicoccum parvum, Parastagonospora nodorum, Penicillium rubens, Pestalotiopsis fici, Pseudozyma hubeiensis, Sordaria macrospora, Thielavia terrestris, Trametes versicolor, Verticillium alfalfae, and Wallemia ichthyophaga. Facultatively pathogenic species like Aspergillus flavus, Candida orthopsilosis, Candida parapsilosis, and Fusarium pseudograminearum without relation to the histologically diagnosed disease were also among the three most frequently detected species.

The abundance or absence of sequences of fungi with potential etiological relevance in line with the histological diagnoses of the fungal sample collection was also studied in all samples (see "Materials and Methods" for the selection of the assessed fungi). The species detected, the average percentage of the corresponding reads in all samples ( \pm 1 standard deviation), and the average percentage of respective reads as a proportion of the fungal reads ( \pm 1 standard deviation) are shown in Table 2. If genera listed in the "Materials and Methods" section are not represented in Table 2, no corresponding detectable reads were found in any of the assessed samples.

Since mycetoma can also be caused by bacteria, the same approach was adopted for relevant bacterial species. This is illustrated in Table 3.

The results for Entamoeba spp., E. histolytica and E. dispar, are given in Table 4.

In a diagnostic total genomic survey such as occurs in NGS analysis, relevant pathogens must be distinguished from random contamination events in the context of sample preparation. It was therefore investigated how the proportions of pathogen-specific reads in cases of etiologic relevance differ from accidental contamination events. For this, it was determined for which samples the detected percentage of reads per pathogenic species exceeded the 1st, 2nd, 3rd, or 4th standard deviation from the mean of all samples and whether the results were consistent with the histological diagnoses. The results of the screenings for pathogenic fungi in the patients with fungal infections are shown with the focus on the percentage of the total number of reads in Table 5 and on the percentage of fungus-specific reads in Table 6. Table 7 provides a corresponding overview for the amebas.

For the assessment based on the total number of reads, detection of potentially relevant fungal species above the 4th standard deviation succeeded in 5 samples, above the 3rd standard deviation in 1 sample, above the 2nd standard deviation in 4 samples, and in 8 samples pathogens were detected above the 1st standard deviation above the mean. No such increased quantities were detected for 5 samples. In all of the 5 samples with fungus detection above the 4th standard deviation, the findings agreed with the histological result. The single detection above the 3rd standard deviation did not agree with the histological result. For the 4 samples with positive results above the 2nd standard deviation, there was a match in 1 case and a mismatch in the 3 other cases. For the 8 samples with fungal detection above the 1st standard deviation, matching was found in 1 case and mismatching in the other 7 cases (Table 5).

Of note, fungal sequences were also found in the 6 biopsies from the gut of the patients with invasive amebiasis. Compared with the total numbers of reads, detections above the 4th standard deviation occurred in 16 instances (0.02\% Pythium ultimum, 0.000009\% Exophiala pisciphila, 0.0001\% Sporothrix schenckii, 0.00002\% Mortierella verticillata, $0.00003 \%$ Cryptococcus stepposus, $0.002 \%$ Setosphaeria turcica, $0.002 \%$ Leptosphaeria maculans, 0.00002\% Fusarium solani, 0.0001\% Cryptococcus victoriae, 0.00002\% Cryptococcus tronadorensis, 0.0002\% Cryptococcus gattii, $0.0002 \%$ Cladosporium cladosporioides, 0.0003\% Capronia coronata, 0.0009\% Bipolaris zeicola, $0.001 \%$ Bipolaris sorokiniana, $0.001 \%$ Bipolaris oryzae). Detections above the 3rd standard deviation succeeded in 4 instances (0.009\% Aspergillus spp., 0.0003\% Cladophialophora carrionii, $0.0008 \%$ Paracoccidioides brasiliensis, $0.00002 \%$ Acremonium chrysogenum), above the 2nd standard deviation in 10 instances $(0.0006 \%$ Capronia epimyces, $0.0004 \%$ Chaetomium thermophilum var. Thermophilum, $0.0002 \%$ Cryptococcus neoformans, $0.0002 \%$ Exophiala dermatitidis, $0.0005 \%$ Paracoccidioides sp. 'lutzii', 0.0002\% Cladophialophora psammophila, 0.000005\% Exophiala pisciphila, $0.0004 \%$ Coccidioides immitis, 0.0004\% Coccidioides posadasii, 0.00001\% Fusarium solani), and above the 1st standard deviation in 11 instances $(0.000008$ and $0.00001 \%$ Aspergillus spp., respectively, 0.00008\% Cladosporium cladosporioides, $0.0003 \%$ Coccidioides immitis, $0.0003 \%$ Coccidioides posadasii, $0.0002 \%$ (in three instances) Cyphellophora europaea, 0.0001\% Fusarium graminearum, 0.0007\% Leptosphaeria maculans, $0.0004 \%$ Paracoccidioides sp. 'lutzii').

On a comparison with the fungal reads only, there were 5 detections above the 4th standard deviation, 1 detection above the 3rd standard deviation, 4 detections above the 2nd standard deviation, and 6 detections above the 1st standard deviation. Although all detections above the 4th standard deviation and 2 out of 4 detections above the 2nd standard deviation matched the histological findings, no other results matched the histological diagnoses (Table 6).

Again, there were fungal sequences in the 6 biopsies from the gut of the patients with invasive amebiasis. 
Table 2 Detectable fungal species and their relative proportion of reads in the samples

\begin{tabular}{|c|c|c|}
\hline Species & $\begin{array}{l}\text { Mean percentage of reads in the sample } \\
( \pm 1 \text { standard deviation) }\end{array}$ & $\begin{array}{l}\text { Mean percentage of fungal reads in the sample } \\
\text { ( } \pm 1 \text { standard deviation) }\end{array}$ \\
\hline Aspergillus spp. & $0.001967 \% \pm 0.001822 \%$ & $2.2087 \% \pm 1.6228 \%$ \\
\hline Acremonium chrysogenum & $0.000002 \% \pm 0.000005 \%$ & $0.0081 \% \pm 0.0260 \%$ \\
\hline Bipolaris oryzae & $0.000110 \% \pm 0.000218 \%$ & $0.1420 \% \pm 0.2276 \%$ \\
\hline Bipolaris sorokiniana & $0.000090 \% \pm 0.000210 \%$ & $0.0891 \% \pm 0.1922 \%$ \\
\hline Bipolaris zeicola & $0.000085 \% \pm 0.000187 \%$ & $0.1272 \% \pm 0.2026 \%$ \\
\hline Capronia coronata & $0.000046 \% \pm 0.000063 \%$ & $0.0586 \% \pm 0.0775 \%$ \\
\hline Capronia epimyces & $0.000177 \% \pm 0.000162 \%$ & $0.2813 \% \pm 0.3244 \%$ \\
\hline Chaetomium globosum & $0.000197 \% \pm 0.000137 \%$ & $0.2739 \% \pm 0.2444 \%$ \\
\hline Chaetomium thermophilum var. Thermophilum & $0.000092 \% \pm 0.000112 \%$ & $0.1204 \% \pm 0.1443 \%$ \\
\hline Cladophialophora carrionii & $0.000058 \% \pm 0.000068 \%$ & $0.1014 \% \pm 0.1472 \%$ \\
\hline Cladophialophora psammophila & $0.000060 \% \pm 0.000064 \%$ & $0.0989 \% \pm 0.1323 \%$ \\
\hline Cladophialophora yegresii & $0.001570 \% \pm 0.001623 \%$ & $1.2943 \% \pm 1.1669 \%$ \\
\hline Cladosporium cladosporioides & $0.000017 \% \pm 0.000045 \%$ & $0.0422 \% \pm 0.0986 \%$ \\
\hline Coccidioides immitis & $0.000093 \% \pm 0.000109 \%$ & $0.1463 \% \pm 0.2174 \%$ \\
\hline Coccidioides posadasii & $0.000094 \% \pm 0.000133 \%$ & $0.1209 \% \pm 0.1931 \%$ \\
\hline Cryptococcus carnescens & $0.000000 \% \pm 0.000002 \%$ & $0.0004 \% \pm 0.0021 \%$ \\
\hline Cryptococcus gattii & $0.000021 \% \pm 0.000043 \%$ & $0.0221 \% \pm 0.0480 \%$ \\
\hline Cryptococcus neoformans & $0.000041 \% \pm 0.000061 \%$ & $0.0559 \% \pm 0.0865 \%$ \\
\hline Cryptococcus stepposus & $0.000001 \% \pm 0.000006 \%$ & $0.0026 \% \pm 0.0125 \%$ \\
\hline Cryptococcus tronadorensis & $0.000001 \% \pm 0.000004 \%$ & $0.0009 \% \pm 0.0042 \%$ \\
\hline Cryptococcus victoriae & $0.000004 \% \pm 0.000021 \%$ & $0.0043 \% \pm 0.0209 \%$ \\
\hline Cyphellophora europaea & $0.000076 \% \pm 0.000111 \%$ & $0.1233 \% \pm 0.1819 \%$ \\
\hline Exophiala dermatitidis & $0.000033 \% \pm 0.000057 \%$ & $0.0422 \% \pm 0.0670 \%$ \\
\hline Exophiala pisciphila & $0.000001 \% \pm 0.000002 \%$ & $0.0017 \% \pm 0.0064 \%$ \\
\hline Fusarium graminearum & $0.000035 \% \pm 0.000047 \%$ & $0.0440 \% \pm 0.0743 \%$ \\
\hline Fusarium pseudograminearum & $0.000978 \% \pm 0.004153 \%$ & $0.8826 \% \pm 3.3271 \%$ \\
\hline Fusarium solani & $0.000001 \% \pm 0.000005 \%$ & $0.0022 \% \pm 0.0074 \%$ \\
\hline Histoplasma capsulatum & $0.001019 \% \pm 0.004143 \%$ & $1.6474 \% \pm 7.0562 \%$ \\
\hline Leptosphaeria maculans & $0.000243 \% \pm 0.000419 \%$ & $0.3583 \% \pm 0.4897 \%$ \\
\hline Madurella mycetomatis & $0.000045 \% \pm 0.000208 \%$ & $0.1752 \% \pm 0.8338 \%$ \\
\hline Mortierella verticillata & $0.000001 \% \pm 0.000004 \%$ & $0.0013 \% \pm 0.0063 \%$ \\
\hline Paracoccidioides brasiliensis & $0.000156 \% \pm 0.000189 \%$ & $0.1896 \% \pm 0.2083 \%$ \\
\hline Paracoccidioides sp. 'Iutzii' & $0.000132 \% \pm 0.000156 \%$ & $0.2044 \% \pm 0.2638 \%$ \\
\hline Pythium ultimum & $0.000871 \% \pm 0.004170 \%$ & not classified as a fungus \\
\hline Rhizopus oryzae & $0.000002 \% \pm 0.000008 \%$ & $0.0022 \% \pm 0.0104 \%$ \\
\hline Setosphaeria turcica & $0.000240 \% \pm 0.000425 \%$ & $0.3191 \% \pm 0.4822 \%$ \\
\hline Sporothrix schenckii & $0.000005 \% \pm 0.000021 \%$ & $0.0096 \% \pm 0.0417 \%$ \\
\hline
\end{tabular}

Compared with the total numbers of fungal reads only, detections above the 4th standard deviation occurred in 8 instances $(0.2 \%$ Sporothrix schenckii, $0.03 \%$ Mortierella verticillata, $0.03 \%$ Exophiala pisciphila, $0.1 \%$ Cryptococcus victoriae, $0.02 \%$ Cryptococcus tronadorensis, $0.06 \%$ Cryptococcus stepposus, $0.9 \%$ Coccidioides posadasii, 0.9\% Bipolaris sorokiniana), above the 3rd standard deviation in 14 instances (8\% Aspergillus spp., 0.1\% Acremonium chrysogenum, 0.9\% Bipolaris oryzae, 0.8\% Bipolaris zeicola, 0.3\% Capronia coronata, 0.4\% Cladosporium cladosporioides, 1\% Coccidioides immitis, $0.2 \%$ Cryptococcus gattii, 0.7\% Cyphellophora europaea, 0.3\% Fusarium graminearum, 0.3\% Fusarium solani, 2\% Leptosphaeria maculans, 1\% Paracoccidioides sp. 'lutzii', 2\% Setosphaeria turcica), above 
Table 3 Detectable bacterial species and their relative proportion of reads in the samples

\begin{tabular}{lll}
\hline Species & $\begin{array}{l}\text { Mean percentage of } \\
\text { reads in the sample } \\
( \pm 1 \text { standard deviation })\end{array}$ & $\begin{array}{l}\text { Mean percentage of bacterial r } \\
\text { eads in the sample } \\
( \pm 1 \text { standard deviation })\end{array}$ \\
\hline $\begin{array}{l}\text { Nocardia } \\
\text { brasiliensis }\end{array}$ & $0.021 \% \pm 0.020 \%$ & $0.097 \% \pm 0.072 \%$ \\
$\begin{array}{l}\text { Nocardia } \\
\text { cyriacigeorgica }\end{array}$ & $0.009 \% \pm 0.009 \%$ & $0.044 \% \pm 0.029 \%$ \\
$\begin{array}{l}\text { Nocardia } \\
\text { farcinica }\end{array}$ & $0.020 \% \pm 0.019 \%$ & $0.087 \% \pm 0.066 \%$ \\
$\begin{array}{l}\text { Streptomyces } \\
\text { spp. }\end{array}$ & $0.458 \% \pm 0.428 \%$ & $2.283 \% \pm 1.494 \%$ \\
\hline
\end{tabular}

the 2nd standard deviation in 13 instances $(0.8 \%$ Paracoccidioides sp. 'lutzii', 0.7\% (twice) Paracoccidioides brasiliensis, 0.2\% Fusarium solani, 0.2\% Fusarium graminearum, 0.2\% Exophiala dermatitidis, 0.5\% Cyphellophora europaea, 0.3\% Cryptococcus neoformans, 0.4\% Cladophialophora psammophila, 0.4\% Cladophialophora carrionii, 1\% Capronia epimyces, 0.6\% Bipolaris oryzae, 0.8\% Acremonium chrysogenum), and above the 1st standard deviation in 30 instances (4\% Aspergillus spp., 0.4\% Bipolaris oryzae, 0.3\% Bipolaris sorokiniana, 0.4 and 0.5\% Bipolaris zeicola, respectively, 0.2\% (twice) Capronia coronata, 0.9\% Capronia epimyces, 0.4 and $0.3 \%$ (three times) Chaetomium thermophilum var. Thermophilum, respectively, 0.3\% Cladophialophora carrionii, $0.3 \%$ (twice) Cladophialophora psammophila, 0.1\% Cryptococcus gattii, 0.2\% (twice) Cryptococcus neoformans, $0.4 \%$ Cyphellophora europaea, 0.009\% Exophiala pisciphila, 1 and 0.9\% Leptosphaeria maculans, respectively, $0.4 \%$ (three times) Paracoccidioides brasiliensis, 0.5\% Paracoccidioides sp. 'lutzii', 1\% (twice) and $0.9 \%$ Setosphaeria turcica, respectively).

The partial mismatch between the comparisons with the whole of the reads and the comparisons with the fungal reads only in the fungal samples is due to the considerable differences in the proportions of assignable reads as well as eukaryotic, bacterial, and viral reads (see above). Matching of results above the fourth standard deviation was found for all reads and fungal reads only; only two other cases (samples 9 and 10) showed matches, and those above only the first standard deviation. There is striking concordance of the two positive detections in pan-fungal PCRs, histology, and NGS

Table 4 Mean percentage of reads of Entamoeba spp., $E$. histolytica and E. dispar in the samples

\begin{tabular}{ll}
\hline Species & $\begin{array}{l}\text { Mean percentage of reads in } \\
\text { the sample }( \pm 1 \text { standard deviation })\end{array}$ \\
\hline Entamoeba spp. & $0.000560 \% \pm 0.002061 \%$ \\
E. histolytica & $0.000398 \% \pm 0.001875 \%$ \\
E. dispar & $0.000109 \% \pm 0.000107 \%$ \\
\hline
\end{tabular}

results (Tables 5 and 6). Even the species Madurella mycetomatis, which accounted for only $4 \%$ of fungal reads, was amplified preferentially in one of the pan-fungal PCRs. Examples such as Histoplasma capsulatum in sample 14 and Madurella mycetomatis in sample 17 also show that a high percentage of specific reads of a pathogen can give a hint on its potential etiologic relevance. This did not apply, however, to all cases under investigation (for example, samples 4, 5). In addition, the percentage of reads of fungi from the environment was quantitatively dominant in nearly all cases with the exception of sample 14. Thus, no compelling association between etiologic plausibility and quantitative proportion of detected reads was confirmed.

Only results above the first and second standard deviation above the mean value were observed for reads of relevant actinomycetoma-associated bacteria (Nocardia and Streptomyces). Based on the totality of reads, Nocardia brasiliensis (0.06\%, histologically rhinosporidiosis) was measured once above the 2nd standard deviation. Above the 1st standard deviation, Nocardia brasiliensis was found in 7 cases $(5 \times 0.4 \%, 2 \times 0.5 \%$; histologically 1 chromoblastomycosis, 1 coccidioidomycosis, 1 histoplasmosis, 1 histoplasmosis or cryptococcosis, 1 mucormycosis, only 1 myzetoma, and 1 rhinosporidiosis), the same as for Nocardia cyriacigeorgica $(7 \times 0.2 \%$; histologically 1 coccidioidomycosis, 1 histoplasmosis, 1 histoplasmosis or cryptococcosis, 1 mucormycosis, only 1 myzetoma, and 2 cases of rhinosporidiosis). For Nocardia farcinica 8 cases $(6 \times 0.04 \%, 2 \times 0.05 \%)$ and for Streptomyces spp., eight cases $(2 \times 0.9 \%, 6 \times 1 \%)$ (histologically 1 chromoblastomycosis, 1 coccidioidomycosis, 1 histoplasmosis, 1 histoplasmosis or cryptococcosis, 1 mucormycosis, only 1 myzetoma and 2 cases of rhinosporidiosis) were detected. Compared with the total number of reads, there were no detections above any standard deviation in the ameba samples. In relation to the bacteria-specific reads, there were detections above only the 1st standard deviation in the fungal samples. This involved Nocardia brasiliensis $(6 \times 0.2 \%)$ and Streptomyces spp. $(6 \times 4 \%)$ in 6 samples (histologically 2 chromoblastomycosis, 1 mucormycosis, 2 mycetoma, and 1 rhinosporidiosis); Nocardia cyriacigeorgica $(5 \times 0.07 \%)$ in 5 samples (histologically 1 chromoblastomycosis, 1 histoplasmosis, 1 mucormycosis, 1 mycetoma, and 1 rhinosporidiosis); and Nocardia farcinica in 3 samples $(3 \times$ $0.2 \%$ ) (histologically 1 chromoblastomycosis, 1 mucormycosis, 1 mycetoma). In samples from patients with invasive amebiasis, Nocardia cyriacigeorgica $(0.1 \%)$ was once above the 2nd standard deviation and Nocardia farcinica $(0.2 \%)$ was once above the 1 st standard deviation compared with the bacteria-specific reads.

Among the 6 assessed ameba samples, there were 2 samples with high ameba density microscopically in 
Table 5 Comparison of the NGS Results in Terms of Percentage of Species-specific Reads of Investigated Fungal Species Per Total Number of Reads in the Sample with the Respective Largest Standard Deviation above the Mean of All Samples in Multiples of the Standard Deviation (SD), Depicted for the Samples from Patients with Invasive Mycoses. "Positive" = matching of the molecular results with histology. "Negative" = inconsistency of molecular results with histology. "Partially positive" = detection of both matching and nonmatching molecular results compared with histology. "Contaminated" = Detection of environmental fungi only. "Match" = NGS result matching the histological findings. "Mismatch" = NGS results not matching the histological findings, "No match" = No evidence for relevant fungal species above the respective standard deviation (SD), "Not performed" in "Specific PCR" = No specific PCR performed. Highest standard deviations (SD) are shown

\begin{tabular}{|c|c|c|c|c|c|c|c|}
\hline Sample & Histological diagnosis & Specific PCR [13] & Panfungal PCRs [13] & NGS $>1$ st SD & $N G S>2$ nd SD & NGS $>3$ rd SD & $\mathrm{NGS}>4$ th $\mathrm{SD}$ \\
\hline 1 & Chromoblastomycosis & Not performed & Contaminated & Match $^{d}$ & No match & No match & No match \\
\hline 2 & Mucormycosis & Negative & Contaminated & No match & No match & No match & No match \\
\hline 3 & Histoplasmosis & Negative & Contaminated & Mismatch ${ }^{e}$ & Mismatch $^{f}$ & No match & No match \\
\hline 4 & Mucormycosis & Positive $^{a}$ & Contaminated & No match & No match & No match & Match $^{9}$ \\
\hline 5 & Histoplasmosis or cryptococcosis & Negative & Contaminated & No match & No match & No match & Match $^{\text {h }}$ \\
\hline 6 & Chromoblastomycosis & Not performed & Contaminated & Mismatch ${ }^{i}$ & Match $^{j}$ & No match & No match \\
\hline 7 & Rhinosporidiosis & Not performed & Contaminated & No match & No match & No match & No match \\
\hline 8 & Mycetoma & Not performed & Contaminated & Mismatch $^{k}$ & Mismatch' & No match & Match $^{m}$ \\
\hline 9 & Rhinosporidiosis & Not performed & Contaminated & Mismatchn & No match & No match & No match \\
\hline 10 & Mycetoma & Not performed & Contaminated & Mismatch $^{\circ}$ & No match & No match & No match \\
\hline 11 & Histoplasmosis & Negative & Contaminated & No match & No match & No match & No match \\
\hline 12 & Histoplasmosis & Negative & Contaminated & Mismatch ${ }^{P}$ & Mismatch ${ }^{q}$ & Mismatch ${ }^{r}$ & No match \\
\hline 13 & Chromoblastomycosis & Not performed & Contaminated & No match & No match & No match & No match \\
\hline 14 & Histoplasmosis & Positive & Partially positive ${ }^{b}$ & No match & No match & No match & Match $^{5}$ \\
\hline 15 & Coccidioidomycosis & Not performed & Contaminated & Mismatch $^{t}$ & No match & No match & No match \\
\hline 16 & Coccidioidomycosis & Not performed & Contaminated & No match & No match & No match & No match \\
\hline 17 & Mycetoma & Not performed & Partially positive ${ }^{c}$ & No match & No match & No match & Match $^{\mathrm{u}}$ \\
\hline
\end{tabular}

a Lichtheimia / Absidia corymbifera, ${ }^{\mathrm{b}}$ Histoplasma capsulatum in 2 out of 5 panfungal PCRs, ${ }^{\mathrm{c}}$ Madurella mycetomatis in 1 out of 5 panfungal PCRs, ${ }^{\mathrm{d}} 0.004 \%$ Cladophialophora yegresii, ${ }^{\mathrm{e}} 0.0004 \%$ Capronia epimyces, ${ }^{\mathrm{f}} 0.0002 \%$ Cladophialophora carrionii, ${ }^{\mathrm{g}} 0.00004 \%$ Rhizopus oryzae, ${ }^{\mathrm{h}} 0.00001 \%$ Cryptococcus carnescens, ${ }^{\mathrm{i}} 0.00009 \%$ Fusarium graminearum, ${ }^{\mathrm{j}} 0.0002 \%$ Cladophialophora psammophila, ${ }^{\mathrm{k}} 0.0004 \%$ Bipolaris oryzae, ' $0.0005 \%$ Paracoccidioides sp. 'lutzii', $\mathrm{m}^{0.02 \%}$ Fusarium pseudograminearum, ${ }^{\mathrm{n}} 0.004 \%$ Cladophialophora yegresii, ${ }^{\circ} 0.004 \%$ Cladophialophora yegresii, ${ }^{\mathrm{P}} 0.0003 \%$ Bipolaris sorokiniana, $0.004 \%$ Cladophialophora yegresii, 0.0003\% Coccidioides immitis, 0.0004\% Paracoccidioides sp. 'lutzii', ${ }^{9} 0.0006 \%$ Capronia epimyces, $0.0006 \%$ Chaetomium globosum, 0.0004\% Chaetomium thermophilum var. Thermophilum, $0.0002 \%$ Cladophialophora psammophila, $0.0002 \%$ Cryptococcus neoformans, $0.0002 \%$ Exophiala dermatitidis, $0.0006 \%$ Paracoccidioides brasiliensis, ${ }^{\mathrm{r}} 0.0005 \%$ Coccidioides posadasii, $0.0005 \%$ Cyphellophora europaea, $0.0002 \%$ Fusarium graminearum, $0.02 \%$ Histoplasma capsulatum, ${ }^{\mathrm{t}} 0.004 \%$ Cladophialophora yegresii, ${ }^{\mathrm{u}} 0.001 \%$ Madurella mycetomatis. Matches with the histological findings are depicted in underlined print

adjacent histological sections and positive E. histolytica PCR; 1 sample with only few amebas in histology in neighboring sections and only questionable positive PCR (cycle threshold value $>35$ ); 1 sample with a positive microscopic result that was questionable due to a very low parasite density in adjacent histological sections and negative PCR; as well as 2 samples with negative histology in adjacent sections and negative PCR results. Sequences of E. histolytica (0.009\%) and Entamoeba spp. $(0.01 \%)$ were detected by NGS above the 4 th standard deviation in comparison with the total number of reads in the samples in one of the strongly positive samples in histology and PCR. In the same sample, sequences were assigned to the phylogenetically closely related $E$. dispar (0.0004\%) above the 2nd standard deviation. Entamoeba spp. sequences above the first standard deviation were also detected in the sample with a few histologically visible amebas and a questionable PCR result (0.0003\%) and in one of the two samples with negative PCR and negative histology (0.0004\%) (Table 7). Furthermore, there were Entamoeba spp.-specific sequences above the 2nd standard deviation $(0.0005 \%)$ in one chromoblastomycosis sample and above the 1st standard deviation $(0.0003 \%)$ in a mycetoma sample. E. dispar-specific sequences were detected in the latter two samples above the 1st standard deviation (each $0.0003 \%$ ) as well.

\section{Discussion}

The NGS technology offers a molecular biological diagnostic tool that allows pathogen detection in complex sample material without prior specific suspicion, if an adequate sequence depth can be guaranteed. The question of adequate sequence depth for metagenomic analyses is not easily answered, in particular, if the proportion of pathogen DNA within a sample is unknown. Most recently, it was suggested by Hillmann et al. (https://www.biorxiv.org/content/biorxiv/early/2018/ 
Table 6 Comparison of the NGS Results in Terms of Percentage of Species-specific Reads of Investigated Fungal Species Per Total Number of Fungal Reads Only in the Sample with the Respective Largest Standard Deviation above the Mean of All Samples in Multiples of the Standard Deviation (SD), Depicted for the Samples from Patients with Invasive Mycoses. "Positive" = matching of the molecular results with histology. "Negative" = inconsistency of molecular results with histology. "Partially positive" = detection of both matching and nonmatching molecular results compared with histology. "Contaminated" = Detection of environmental fungi only. "Match" = NGS result matching the histological findings. "Mismatch" = NGS results not matching the histological findings, "No match" = No evidence for relevant fungal species above the respective standard deviation (SD), "Not performed" in "Specific PCR" = No specific PCR performed. Highest standard deviations (SD) are shown

\begin{tabular}{|c|c|c|c|c|c|c|c|}
\hline Sample & Histological diagnosis & Specific PCR [13] & Panfungal PCRs [13] & NGS > 1st SD & $N G S>2 n d S D$ & $\mathrm{NGS}>3 \mathrm{rd} \mathrm{SD}$ & $\mathrm{NGS}>4$ th $\mathrm{SD}$ \\
\hline 1 & Chromoblastomycosis & Not performed & Contaminated & No match & Match $^{d}$ & No match & No match \\
\hline 2 & Mucormycosis & Negative & Contaminated & Mismatche & No match & No match & No match \\
\hline 3 & Histoplasmosis & Negative & Contaminated & Mismatch $^{f}$ & Mismatch $^{\mathrm{g}}$ & Mismatch $^{\text {h }}$ & No match \\
\hline 4 & Mucormycosis & Positive $^{a}$ & Contaminated & No match & No match & No match & Match $^{\mathrm{i}}$ \\
\hline 5 & Histoplasmosis or cryptococcosis & Negative & Contaminated & No match & No match & No match & Match $^{j}$ \\
\hline 6 & Chromoblastomycosis & Not performed & Contaminated & No match & Match $^{k}$ & No match & No match \\
\hline 7 & Rhinosporidiosis & Not performed & Contaminated & No match & No match & No match & No match \\
\hline 8 & Mycetoma & Not performed & Contaminated & No match & No match & No match & Match' \\
\hline 9 & Rhinosporidiosis & Not performed & Contaminated & Mismatch $^{m}$ & No match & No match & No match \\
\hline 10 & Mycetoma & Not performed & Contaminated & Mismatch $^{n}$ & No match & No match & No match \\
\hline 11 & Histoplasmosis & Negative & Contaminated & No match & No match & No match & No match \\
\hline 12 & Histoplasmosis & Negative & Contaminated & No match & No match & No match & No match \\
\hline 13 & Chromoblastomycosis & Not performed & Contaminated & No match & No match & No match & No match \\
\hline 14 & Histoplasmosis & Positive & Partially positive ${ }^{b}$ & Mismatch $^{\circ}$ & No match & No match & Match $^{p}$ \\
\hline 15 & Coccidioidomycosis & Not performed & Contaminated & No match & No match & No match & No match \\
\hline 16 & Coccidioidomycosis & Not performed & Contaminated & No match & No match & No match & No match \\
\hline 17 & Mycetoma & Not performed & Partially positive ${ }^{c}$ & Mismatch ${ }^{q}$ & Mismatch $^{r}$ & No match & Match $^{5}$ \\
\hline
\end{tabular}

${ }^{a}$ Lichtheimia / Absidia corymbifera, ${ }^{b}$ Histoplasma capsulatum in 2 out of 5 panfungal PCRs, ${ }^{c}$ Madurella mycetomatis in 1 out of 5 panfungal PCRs, ${ }^{\mathrm{d}} 4 \%$ Cladophialophora yegresii, ${ }^{\mathrm{e}} 3 \%$ Cladophialophora yegresii, ${ }^{\mathrm{f}} 0.2 \%$ Cryptococcus neoformans, $0.6 \%$ Chaetomium globosum, ${ }^{\mathrm{g}} 1 \%$ Capronia epimyces, ${ }^{\mathrm{h}} 0.6 \%$ Cladophialophora carrionii, ${ }^{\mathrm{i}} 0.05 \%$ Rhizopus oryzae, ${ }^{\mathrm{j}} 0.01 \%$ Cryptococcus carnescens, ${ }^{\mathrm{k}} 0.8 \%$ Chaetomium globosum, $0.4 \%$ Cladophialophora psammophila, ${ }^{\prime} 16 \%$ Fusarium pseudograminearum, ${ }^{m_{3}}$ \% Cladophialophora yegresii, ${ }^{n} 3 \%$ Cladophialophora yegresii, ${ }^{\circ} 0.09 \%$ Cryptococcus gattii, $0.4 \%$ Paracoccidioides brasiliensis, $\mathrm{p}_{34 \%}$ Histoplasma capsulatum, ${ }^{\mathrm{q}} 0.7 \%$ Capronia epimyces, ${ }^{\mathrm{r}} 0.2$ Exophiala dermatitidis, $0.5 \%$ Chaetomium thermophilum var. Thermophilum, $1 \%$ Chaetomium globosum, ${ }^{5} 4 \%$ Madurella mycetomatis, Matches with the histological findings are depicted in underlined print

Table 7 Comparison of the NGS Results in Terms of Percentage of Species-specific Reads of Investigated Entamoeba spp., Entamoeba histolytica, and Entamoeba dispar Per Total Number of Reads in the Sample with the Respective Largest Standard Deviation above the Mean of All Samples in Multiples of the Standard Deviation (SD), Depicted for the Samples from Patients with Invasive Amebiasis. "Positive" = positive Entamoeba histolytica PCR. "Negative" = negative Entamoeba histolytica PCR. "Uncertain" (for "Specific PCR") = High cycle threshold value $>35$ in real-time PCR with associated uncertain interpretation. "Uncertain" (for "Microscopy in neighboring slides") = Extremely low parasite density with associated uncertain interpretation. "Match" = NGS result matching the diagnosis "invasive amebiasis". "Partial match" = NGS result matching the diagnosis "invasive mycosis" on genus level only, so it is neither confirmed nor completely rejected, "Mismatch" = NGS results not matching the diagnosis "invasive amebiasis", "No match" = No evidence of specific sequences above the respective standard deviation (SD). Highest standard deviations (SD) are shown

\begin{tabular}{|c|c|c|c|c|c|c|c|}
\hline Sample & Histological diagnosis & Specific PCR [7] & Microscopy in neighboring slides [7] & NGS > 1st SD & NGS > 2nd SD & NGS > 3rd SD & $\mathrm{NGS}>4$ th $\mathrm{SD}$ \\
\hline 18 & Invasive amebiasis & Positive & Many amebae & No match & No match & No match & No match \\
\hline 19 & Invasive amebiasis & Negative & Negative & No match & No match & No match & No match \\
\hline 20 & Invasive amebiasis & Positive & Many amebae & No match & Mismatch $^{a}$ & No match & Match $^{b}$ \\
\hline 21 & Invasive amebiasis & Uncertain & Few amebae & Partial match ${ }^{c}$ & No match & No match & No match \\
\hline 22 & Invasive amebiasis & Negative & Negative & No match & No match & No match & No match \\
\hline 23 & Invasive amebiasis & Negative & Uncertain & Partial match ${ }^{d}$ & No match & No match & No match \\
\hline
\end{tabular}

${ }^{\mathrm{a}} 0.0004 \%$ Entamoeba dispar, ${ }^{\mathrm{b}} 0.009 \%$ Entamoeba histolytica and $0.01 \%$ Entamoeba spp., ${ }^{\mathrm{c}} 0.0003 \%$ Entamoeba spp., ${ }^{\mathrm{d}} 0.0004 \%$ Entamoeba spp. 
05/12/320986.full.pdf, last accessed on 1 August 2018) that shallow metagenomic analysis effectively probes the diversity of species down to a sequencing depth of $500 \mathrm{k}$ reads per sample. Even better sequence depth was achieved for all described samples by our sequencing approach.

The technological approaches of NGS are varied [9, 19-25] and some are still in the stage of development or optimization. A descriptive overview on NGS for the diagnosis of infectious diseases was introduced by Hasman and colleagues [26]. In a previous study, an association between infectious agents and a disease of unknown origin was confirmed [14]. Further, NGS-based detection of bacterial pathogens from two-thirds of tested urine samples was demonstrated in a previous "proof-of-principle" investigation [26]. NGS is also suitable for the detection of poly-microbial infections, as was shown for sample material from brain abscesses [27]. The most reliable diagnostic information can be provided by NGS from primary sterile sample material, where few reads can be used for pathogen diagnostics. Thus Wilson and colleagues succeeded in demonstration of Leptospir$a$-induced meningoencephalitis with NGS based on only 475 (out of more than 3 million) specific reads [28]. Pathogen identification with NGS-based analysis of RNA (ribonucleic acid) in the sample material is also possible and succeeded in recognizing RNA viruses such as influenza virus in respiratory samples in the so-called UMERS ("unbiased metagenomic nontargeted RNA sequencing") approach [29].

Although the NGS technology is still expensive, sequencing costs have dropped dramatically. For example, the cost of sequencing a human genome was reduced from about 100,000 euros to about 1000 euros within a few years as a result of technological progress [9]. In particular, the introduction of small automated sequencers (about the size of laser printers) has made NGS technology interesting for diagnostic purposes. An earlier comparative evaluation of these small "workbench" sequencers showed that the MiSeq system (Illumina) that was used in this study is superior to the competitors Ion Torrent PGM (Life Technologies, Carlsbad, CA, USA) and the no-longer available 454 GS Junior (Roche, Basel, Switzerland) with focus on the rarity of sequencing errors [30].

The hitherto quite complex and non-user-friendly analysis of sequence information is currently one of the major limitations of wide diagnostic application of NGS technology [31]. Further automation and standardization are essential to overcome these problems for the application of NGS in diagnostic routine. This also applies to the quality and accessibility of underlying databases.
Although the application of NGS with formalin-fixed, paraffin-embedded tissue is not new [17, 18], the NGS-based detection of etiologically relevant pathogens from such materials is a diagnostic challenge. In addition to previous experiments, we therefore conducted a real-life assessment with sample materials from patients with rare and tropical invasive infections, for which no similar experience is available. Non-pathogen-specific molecular diagnostic approaches such as NGS are easily affected by contamination due to environmental microorganisms that are, for example, cast along with the sample in wax. As shown for Bartonella spp. DNA some years ago [32], DNA cross-contamination during tissue processing in a multispecies histopathological laboratory is highly likely. In the current, still unpublished, EORTC (European Organization for Research and Treatment of Cancer) criteria (personal correspondence with Professor Ralf Bialek) for the detection of a fungal infection from paraffin-embedded tissue by means of PCR, it is explicitly pointed out that the detection of specific fungal DNA in paraffin-embedded tissues shall only be used as proof of infection if fungal elements are also seen in histopathological assessments. This is to make sure that possible contamination of paraffin with ubiquitous fungal spores, for example of Aspergillus spp., is not mistakenly used as evidence of invasive mycosis. Although protocols for optimizing the use of FFPEs in molecular epidemiology by reducing the contamination risk have been introduced [33], initial tissue processing and waxing had been performed in a histopathological standard laboratory, where no special precautions against DNA contamination had been enforced. During the cutting of the sections for the molecular analyses, protective procedures against contamination such as discarding the first cuts of each block had been enforced as detailed elsewhere $[7,13]$. However, such precautions cannot undo contamination with fungal spores or pathogen DNA that has already occurred during initial processing and waxing of the tissue. This problem was also evident in the present study, in terms of both pan-fungal PCRs and the NGS approach. Traces of DNA even of rare tropical pathogens could be identified within the samples. Species-specific PCRs [34-41] are potential alternatives to pan-fungal PCR approaches, but their selection requires a specific diagnostic suspicion.

Traditional histology is not always reliable in case of invasive fungal infections as well. Its reliability is influenced by a variety of factors, including the requirement for a critical minimum density of pathogens in the examined tissue and a high level of expertise of the physician. In comparative studies between histology and culture, the latter of which cannot be performed from formalin-fixed tissues, a match of less than $80 \%$ was demonstrated [42], so histological diagnoses of invasive 
mycoses have to interpreted with caution [36]. In this study, the histological evaluation was performed by experienced pathologists who were professionally experienced in tropical infectious diseases [13]. Particularly considering the large number of genera and species that-as shown in the "Material and Methods" section-may account for the assessed invasive fungal infections, one has to bear in mind that histologically indistinguishable findings may be caused by different agents. In most cases of invasive mycosis in this study, histology did not allow a species-specific diagnosis but only micro-morphological descriptions such as chromoblastomycosis, mucormycosis, or mycetoma. The lack of cultural and serological results makes the interpretation of such findings challenging, which is an undeniable limitation of this study. Molecular approaches can be very useful here if culture is not possible. Even when sampling conditions allow culture approaches, cultural growth is not possible for all invasive fungi and takes between several days and several weeks depending on the species, as summarized elsewhere [13]. These factors reduce the diagnostic value of fungal culture.

A first important precondition for the reliability of molecular diagnostic findings is the quality of the nucleic acid extraction, which in this study was unacceptable for several samples that had been stored for long times. In line with this, partial PCR inhibition was observed in some of the assessed samples, as shown elsewhere [13]. Comparative testing of alternative nucleic acid purification methods $[43,44]$ might have contributed to a further optimization of nucleic acid preparation in this study, but this was impossible due to the small amount of sample material that was available, which is an undeniable limitation of the study. For the samples that could be included in the NGS assessment, no significant Spearman rank correlation between sample age and number of detected reads could be found. However, the heterogeneity of the sample materials used makes an interpretation difficult. Of note, no samples older than 31 years were included.

Since the paraffin blocks were stored with the formalin-fixed tissues for years without any special protective measures against the deposition of fungal spores, contamination with environmental fungal spores can be regarded as highly probable. Thus, the high levels of contamination with environmental fungi are not unexpected. Contamination of the paraffin is an alternative explanation.

The high degree of contamination, expected from the previously applied pan-fungal PCRs [13], was a challenge for the NGS analysis. Since NGS analysis is associated with a completely nonspecific analysis of DNA fragments, the challenge is the discrimination of contaminants and etiologically relevant pathogens. The histological results of the samples from patients with invasive mycosis provided hints but not etiological clarification at the species level.

To overcome this problem, each mean value and standard deviation of the percentages of specific sequence fragments (reads) of etiologically relevant species were determined in the assessed samples. Then, the standard deviation from the average at which matching with the histological results can be expected was investigated.

A high rate of matches between histology and NGS results was found only for percentages above the fourth standard deviation in relation to the total number of reads and the number of fungi-specific reads. In cases with percentages above the fourth standard deviation, clear similarities with histology were found. When the percentages in relation to the totality of the reads in the sample were compared with the percentages in relation to the fungal reads in the sample, there was a considerable deviation, which can be explained by the massive differences in the proportions of assignable reads as well as eukaryotic, bacterial, and viral reads. For samples in which none of the assessed species reached the 4th standard deviation, no reliable assignment of etiological relevance could be performed. In the 6 tested samples from patients with invasive amebiasis, NGS-based detection of E. histolytica succeeded in a single sample only, which had also been positive in histology and was clearly positive by PCR.

The approach of comparing NGS results from nonsterile samples of patients with results from a healthy population to define etiologic relevance is not new. A comparison with negative control samples, which was based on a specific subtraction of reads, has been proposed by other authors as a method for identifying pathogens of potential etiological relevance. In this way, the detection of shiga-toxin-producing Escherichia coli succeeded in $67 \%$ of stool samples of patients during an outbreak [15].

Another approach was chosen for the sample collection assessed in this study. Other than in the recently described study [15], historical sample materials were used in the real-life assessment presented here. Because the samples had not been stored and collected for study purposes but as part of the diagnostic routine, no matched standardized negative control samples had been prepared. The collection of corresponding materials from completely healthy control subjects would also have posed an ethical problem in instances where the materials were derived from severely invasive sampling procedures, e.g., in case of samples from lung tissue, spinous process tissue, or tricuspid valve tissue. In any case it is obviously impossible to retrospectively apply any sort of standardization to samples prepared, paraffinated, and stored under unknown, and presumably 
variable conditions in comparatively low-tech laboratory environments sometimes a considerable time in the past. Although randomly selected blocks from a similar time frame that were negative by histopathology might have helped to establish an expected background, such an approach was not chosen for the above-mentioned reasons.

To overcome the problem of the lack of standardized negative controls, the mean percentages of specific reads from all samples, including histologically positive and negative ones regarding the various assessed species, were considered as proxy-negative control values, representing an averaged background. The repeated summing of the standard deviation values and comparison with the individually measured percentages in each sample allowed an estimation of how many more specific reads were detected in each sample than in the proxy-negative control. Accordingly, a standard deviation-based and not a subtraction-based approach [15] was chosen.

The rationale of the standard deviation-based approach is the assumption that the likelihood of a real infection increases with the number of standard deviations of a percentage of measured specific reads in a specific sample above the proxy-negative control. With a value high above the mean value plus several standard deviations, the risk is low that this percentage is measured by chance, i.e., due to contamination. If bacteria and fungi were assessed, these comparisons were carried out not only with all reads within the samples but also with bacteria- or fungi-specific reads. This was done to reduce the effects of the slightly different proportions of viral, bacterial, fungal, and other eukaryotic reads specific to the sample materials. As amebae are neither fungi nor bacteria, such an approach was not possible for their assessment. As an indication of potential contamination, the percentages of specific reads for all species of the genus Entamoeba and also of specific reads for non-pathogenic amebae such as E. dispar were assessed.

For the fungi and bacteria that were assessed, comparisons of the species-specific reads with the total number of reads and with fungus-specific reads and bacteria-specific reads, respectively, led to slightly different results. For example, there were matches above the 2nd standard deviation for Cladophialophora psammophila compared with the total number of reads and for both Cladophialophora psammophila and Chaetomium globosum compared with the fungus-specific reads in a sample with the histological diagnosis of chromoblastomycosis. Such differences are mathematical artifacts resulting from slightly different proportions of fungus-specific reads in the different sample materials. Such examples demonstrate the vulnerability of the model, which is a particular problem with low sample numbers when slight variances show large effects.
An undeniable limitation of the standard deviation-based approach is the fact that the reliability of the proxy-negative control will depend on the number of assessed samples. However, subtraction-based approaches [15] are also susceptible to the problem of sample numbers in excluding major effects of variations by chance.

It is likely that the variety of anatomical source sites might influence the quality of the proxy-negative control. The fact that samples from primarily sterile body compartments were also severely contaminated with DNA of various non-human species suggests that the effects of procedures subsequent to sample acquisition, e.g., during processing, paraffination and storage, were more relevant to the measured contamination than was the anatomical sampling site. Accordingly, the anatomical site was not specifically considered in the definition of the proxy-negative control for the formalin-fixed, paraffin-embedded tissue samples that were assessed. For medical interpretation of the diagnostic NGS results, however, the natural occurrence of environmental microorganisms on primarily non-sterile sampling sites has to be considered. Thus NGS cannot do away with the need for medical validation and interpretation of diagnostic findings.

No target enrichment, e.g., by specific PCR, was attempted or evaluated because the performance of diagnostic NGS without specific suspicion was being assessed. Depletion of human DNA prior to the NGS runs was also not attempted, because the initial DNA quantities in the historical samples was so low that the appropriate technical strategies might also have affected the recovery of the residual target DNA. As an example of this concern over sensitivity, pro-viral DNA of HIV that would be anticipated to be present was never detected in any sample of the patients with invasive and tropical mycoses. The sensitivity concern is of particular importance, because various matches with the histological diagnoses were achieved with just the standard deviation-based approach for the attribution of etiological relevance, while the total numbers of specific reads were very low. In contrast, etiologically irrelevant environmental fungi dominated among the most frequently detected fungal reads in nearly all samples assessed.

Another pointer toward unlikely etiological relevance but increased likelihood of contamination is the frequent detection of very rare pathogens in various samples. An example is the frequent detection of Cladophialophora yegressii, which lives on living cactus plants [45]. Although Cladophialophora spp. can in rare cases be associated with human disease, i.e. chromoblastomycosis [45], the frequent occurrence of comparably high DNA concentrations in samples without any histological indications for chromoblastomycosis makes it more likely 
that there was contamination deriving from cactus plants in the diagnostic institute.

Further, interpretation can be difficult if increased quantities of sequences of a species are detected which has rarely or never been associated with clinical disease so far. Cryptococcus carnescens is such an example. C. carnescens is part of the Cryptococcus laurentii complex [46]. In a recent review on non-neoformans cryptococcal infections, only 20 cases of infection with C. laurentii complex were reported [47] and those were without detailed differentiation within the complex. The etiological relevance of the $C$. carnescens sequences, which were identified by NGS in sample 5 of a patient with the histological diagnosis of histoplasmosis or cryptococcosis, is therefore uncertain.

Although potentially useful diagnostic information for 5 out of 17 samples from patients with invasive fungal infection (29.4\%) and for 1 out of 6 samples from patients with invasive amebiasis (16.7\%) represents only a modest result, this result must be interpreted in relation to the complexity of the sample materials. The sensitivity of the procedure is, undeniably, still unacceptably poor. In comparison, the molecular gold standard method of pan-fungal PCRs with subsequent Sanger sequencing allowed conclusive detection of pathogens in only 2 out of 17 fungal samples (11.8\%) and even that only in 3 out of 10 PCR reactions for those 2 samples [13]. In contrast, NGS analysis not only allowed confirmation of the pan-fungal PCR detections of Histoplasma capsulatum and Madurella mycetomatis but also gave hints of infections due to Rhizopus spp., Cryptococcus spp., and Fusarium spp. Particularly for assignments at genus and species levels, histology showed limited value for the diagnosis of invasive fungal infections $[36,42]$, as in the study described here. For the detection of Entamoeba histolytica in intestinal biopsies, however, specific PCR proved to be superior to NGS analysis.

Accordingly, NGS analysis can help to improve the molecular discrimination of fungal pathogens in formalin-fixed, paraffin-embedded tissues in comparison with contamination-sensitive pan-fungal PCR with subsequent Sanger sequencing. However, the sensitivity appears inferior to that of specific PCR approaches, as the experiments with the ameba-containing samples suggest. For the invasive fungi, however, quality-controlled specific PCRs were available only for histoplasmosis and mucormycosis in the laboratories of the study participants. Specific analysis for all fungal pathogens could therefore not be performed-an admitted limitation of the study.

Focusing on samples for which results of specific PCR and Sanger sequencing were available, it is interesting that PCR with subsequent Sanger sequencing suggested
Lichtheimia/Absidia corymbifera while NGS gave strong hints for Rhizopus oryzae in sample 4 of a patient with mucormycosis. Preferential amplification of Lichtheimial Absidia corymbifera DNA by the PCR primers is a likely explanation, while the more abundant Rhizopus oryzae-specfic DNA was identified by NGS. Preferential primer binding affinities of multispecies primers to certain microorganisms is a well-known problem affecting amplification-based diagnostic approaches [48].

With focus on the hypothesis of the study, it could be shown that hypothesis-free genomic detection of rare invasive infections by NGS in poly-microbially contaminated, formalin-fixed, paraffin-embedded tissue samples is feasible and can provide hints on likely causative agents. Considering the cost of the technique, the demanding technical and bioinformatic procedures, and the uncertainties regarding the interpretation of the results, the technique at present is still subordinate in the diagnostic workflow and should be only considered if other, less demanding procedures do not lead to conclusive results.

It should be noted that assignment of potential etiological relevance based on a percentage of specific NGS reads is far from being standardized and requires further evaluation. Among other factors, the choice of the number of negative control samples in the calculation of the average of the percentage values of reads will necessarily have an impact on the size of the standard deviation and thus on the potential attribution of etiologic relevance in contaminated sample materials. So, standardization prior to diagnostic use is obligatory. From this perspective, the results presented here can only be considered as hypothesis-forming. Further studies are needed to define standards for medical interpretation of NGS-based pathogen identification directly from sample material. This applies even more strongly for contamination-prone sample materials such as formalin-fixed, paraffin-embedded tissue samples.

For such contamination-prone sample materials, there is considerable risk of false-positive spurious results, e.g., in case of contamination events that are restricted to the processing of individual samples. Such events cannot be controlled by the proxy-negative control-based standard deviation approach. Accordingly, the procedure we have introduced can only lead to hypothesis-forming results that will induce the clinician in charge to consider as differential diagnoses clinically matching infectious diseases that had not been considered prior to the non-specific NGS assessment. Without consideration of the clinical findings, the NGS results from such materials are not interpretable. If these limitations are accepted, however, NGS can help to suggest infectious agents as potentially etiologically relevant that were not considered during the initial clinical assessment of a patient. With this aim, 
the technique can be applied in situations when there are no clear candidates in the potential etiological background of clinical situations in infectious disease patients.

\section{Conclusions}

In conclusion, molecular diagnostic approaches from complex and potentially contaminated sample materials such as formalin-fixed, paraffin-embedded tissues remain a challenge. Similarly to previous studies [14], potentially etiologically relevant species that could not be detected by traditional molecular analysis were identified by NGS. The findings suggest the suitability of the use of NGS-based diagnostics on materials taken under sterile precautions from primary sterile compartments of the body even without a specific etiologic suspicion.

A major disadvantage of pathogen-nonspecific NGS analysis remains the low sensitivity in comparison with specific PCR, which was confirmed by the example of the ameba samples and which was also observed by other authors [49]. Another disadvantage, as addressed in this study, is the high susceptibility to contamination that is frequently observed in formalin-fixed, paraffin-embedded samples. It must further be considered that the procedure described is both expensive and time-consuming. The cost of the reagents employed for this proof-of-principle assessment was about 50,000 euros, apart from payment for the scientists and technical assistants. The diagnostic approaches including the nucleic acid processing, the NGS runs, the programming and application of the required bioinformatics, and the interpretation of the data occupied several weeks. Both the costs and the long time-to-result will impede the use of the procedure for routine-diagnostic purposes in the near future.

Following this "proof-of-principle" study, validations with larger numbers of samples should be performed to define reliable standards for the discrimination of the detection of etiologically relevant pathogens from the detection of nucleic acid contamination, in particular from difficult sample materials.

\section{Methods}

\section{Sample materials}

The materials assessed comprised residual extracted nucleic acids from two previous studies [7, 13], that is, from 17 FFPE tissue samples with histological evidence of invasive mycosis by tropical or rare fungi and 34 samples from patients with invasive amebiasis. Information on the applied nucleic acid extraction procedures is summarized in Table 8.

As detailed below, only 6 out of 34 amebic samples of the original collection [7] could be included into the NGS assessment on the grounds of sufficient quality and quantity of the DNA. The histopathological diagnoses of the patients with invasive mycoses were chromoblastomycosis $(n=3)$, coccidioidomycosis $(n=2)$, histoplasmosis $(n$ $=4$ ), histoplasmosis or cryptococcosis with histologically difficult discriminability $(n=1)$, mucormycosis $(n=2)$, mycetoma $(n=3)$, and rhinosporidiosis $(n=2)$ as detailed elsewhere [13] (Table 9).

Cultural and serological diagnostic results were not available. Further, there were no data on previous molecular diagnostic assessment from the time of sample acquisition or on microscopical assessments from other sample materials, e.g., for ova or parasites from stool samples.

The sample collection included biopsies of the intestinal mucosa $(n=6)$, lymph node tissues $(n=2)$, skin biopsies $(n=6)$, bioptic material from a nasal polyp $(n=$ $1)$, cells from vaginal discharge $(n=1)$, lung tissue $(n=$ 2 ), bone, muscle, and connective tissue from the spinous process of the third thoracic vertebra $(n=1)$, tissue of a tricuspid valve $(n=1)$, a lower lip biopsy $(n=1)$, an ethmoid sinus biopsy $(n=1)$, and bioptic material from a wound on a foot $(n=1)$. The sample age at the time of nucleic acid extraction varied between 1 and 31 years with a mean of 11.5 years $( \pm 6.1)$ in a left-shifted distribution for the fungal samples and with a mean of 25.8 years $( \pm 4.3)$ in a right-shifted distribution for the ameba-containing samples. All samples had been stored in the Department of Pathology of the Bernhard Nocht Institute for Tropical Medicine in Hamburg, Germany.

Nucleic acid extraction procedures have been described elsewhere [7, 13]. Photometric nucleic acid quantification was done as described [13] with a Pico 100 Picodrop Microliter Spectrophotometer (Picodrop Ltd., Hinxton, UK) and indicated DNA concentrations of $123.6( \pm 166.5) \mathrm{ng} / \mu \mathrm{l}$ for the fungal samples and 25.1 $( \pm 30.2) \mathrm{ng} / \mu \mathrm{l}$ for the amebic samples.

In addition to microscopic assessment [7, 13], all amebic samples had been assessed by E. histolytica-specific PCR [7], while the fungal samples had been characterized by five different pan-fungal PCRs with subsequent Sanger sequencing as well as Histoplasma spp-specific and Mucorales-specific PCR, the latter also with Sanger sequencing [13] (Table 10). If sequences of environmental fungi in contradiction to the histological diagnosis were detected by pan-fungal PCR or if sequence overlays made the interpretation of Sanger sequencing results of pan-fungal PCR products impossible, contamination of the samples with environmental fungi was assumed. Table 10 lists all used primers and probes including the inhibition control PCR and the sample quality control PCR. Relevant sample inhibition was not shown for the samples, as detailed elsewhere $[7,13]$. Negative controls also assessing the nucleic acid extraction procedure and the master mixes using PCR-grade water 
Table 8 Nucleic Acid Extraction Procedures As Described Elsewhere $[7,13]$

Common procedures for formalin-fixed, paraffin-embedded (FFPE) samples with histological diagnosis of invasive amebiasis and mycosis

- Exposure of $25 \mu \mathrm{m}$ thick sections in $1.5 \mathrm{ml}$ tubes for $2 \times 10 \mathrm{~min}$ to $1200 \mu \mathrm{l}$ xylene and for $3 \times 10 \mathrm{~min}$ to $1200 \mu \mathrm{l} 100 \%$ ethanol under gentle constant agitation for deparaffination

- Discarding of the supernatant following each 10-min step after centrifugation for $10 \mathrm{~min}$ at $13,000 \mathrm{~g}$

- Air-drying of the samples

Specific procedures as applied for the samples with invasive mycosis

- DNA extraction using the DNA FFPE tissue kit (Qiagen, Hilden, Germany) according to the manufacturer's instruction as follows:

- Proteinase $\mathrm{K}$ digestion at $56^{\circ} \mathrm{C}$ overnight to get a clear suspension

- Lysis of the fungal cell walls in the pellet with 400 units of Arthrobacter luteus lyticase L2524 (Sigma-Aldrich Corporation, St. Louis, MO, USA) (instead of lyticase L4276 [Sigma-Aldrich

Corporation] which was no longer available) per sample for $45 \mathrm{~min}$ at $37^{\circ} \mathrm{C}$

Specific procedures as applied for the samples with invasive amebiasis

- Tissue digestion in $200 \mu$ lysis buffer (0.5\% Tween 20 [ICl, American Limited, Merck, Hohenbrunn, Germany], 2 mg/ml proteinase K [Roche, Mannheim, Germany], $3.5 \mathrm{mM} \mathrm{MgCl} 2,15 \mathrm{mM}$ ammonium sulfate, and $60 \mathrm{mM}$ Tris/HCl [pH 8.5]) for at least $1 \mathrm{~h}$ until a clear lysate was obtained at $56^{\circ} \mathrm{C}$ under continuous shaking

- Boiling for $10 \mathrm{~min}$ to stop the digestion by denaturing the proteinase $\mathrm{K}$

- DNA extraction using the QIAamp DNA Mini Kit (Qiagen) according to the manufacturer's instructions

were included in the PCR procedures. However, only the sample materials were assessed by NGS.

\section{NGS and bioinformatics}

Nonspecific NGS sequencing of the DNA elements within the samples was performed by an experienced medical-laboratory assistant using a MiSeq system (Illumina, San Diego, CA, USA) as described by the manufacturer. No target enrichment or human DNA depletion was attempted. In summary, DNA libraries were prepared using TruSeq ${ }^{\circ}$ Nano DNA Sample Preparation kits (Illumina) employing the low sample (LS) protocol. Briefly, $100 \mathrm{ng}$ of each genomic DNA from the samples was fragmented by Adaptive Focused Acoustics $^{\mathrm{m} \mathrm{m}}$ Technology (Covaris, Inc., Woburn, MA, USA) using a Covaris M220 with settings for fragment sizes in the 350 bp range (duty factor $20 \%$, peak incident power $50 \mathrm{~W}$, cycle per burst 200, duration $65 \mathrm{~s}$, temperature 65 $\left.{ }^{\circ} \mathrm{C}\right)$. Fragmented chromosomal DNA was cleaned up with bead technology. End repair was performed according to the TruSeq protocols. Further clean-up and size selection was done with bead technology. 3 '-Ends were adenylated, Illumina adapters were ligated and DNA fragments were enriched. An Agilent DNA 7500 kit (Agilent Technologies, Inc., Santa Clara, CA, USA) was used as a quality check and for the confirmation of the intended fragment size after the application of the Covaris M220 fragmentation protocol and after Illumina adapter ligation. Visualization of a clearly defined peak in the expected size range was considered as proof of successful DNA fragmentation and adapter ligation. If no peak was visible after applying the fragmentation protocol, the sample was not further analyzed for downstream processing. Only samples with clearly visible peaks in the expected size range, both after fragmentation and after adapter ligation, were further analyzed by sequencing. No concentration determination by integrating the area under the peak was performed, because this was considered as not reliable and sensitive enough for sequencing. Actual library DNA concentration measurements were performed using Qubit dsDNA BR assay kits (Thermo Fisher Scientific, Waltham, MA, USA) prior to loading the sequencing cells.

All 17 fungal samples were included in the further analysis while only 6 amebiasis samples showed visible DNA peaks and could thus be included. The remaining 28 amebiasis samples with visible DNA peaks lacking in the Agilent system were discarded. Each individual library was adjusted to a $4 \mathrm{nmol} / \mathrm{L}$ stock solution and of these 6 pmol was used for each individual sequence run. Sequencing was performed using Reagent Kit MiSeq ${ }^{\circ}$ v3 (600 cycle) runs (Illumina), with a complete v3 run used per sample. Between 3 million and 23 million read pairs were sequenced per sample. Considering an average trimmed read length of $250 \mathrm{bp}$ (base pairs) and an assumed target genome of $30 \mathrm{Mb}$ (mega bases), this would result in theoretical coverages in the range of 45 to 384-fold.

The bioinformatic processing of the resulting files was performed at the Max Planck Institute for Heart and Lung Research in Bad Nauheim, Germany. Paired-end reads were trimmed for adapter sequences using Cutadapt 1.41 [50]. All Truseq adapters were removed using default parameters. The resulting reads were further trimmed and filtered for quality using Trimmomatic 0.33 (LEADING:3, TRAILING:3, SLIDINGWINDOW:5:20, MINLEN:30) [51]. Start and end of reads were always trimmed by a fixed number of 3 nucleotides to remove pervasive low-quality data. Furthermore, reads were trimmed after a drop in average quality below Q20 in a window of 5 nucleotides. Only if both mates of a read-pair still contained more than 30 nucleotides after this, the pair was cleared for further analyses. Kraken version 0.10 .6 was employed to classify metagenomic reads based on matching 31-kmers with a confidence threshold of 0.1 [52]. The reference database consisted of genomes (".genomic.fna.gz) of all bacteria, viruses, fungi, and protozoa, as well as Homo sapiens available from the RefSeq database on September 14, 
Table 9 Histological Characterization of Neighboring Sections of the Materials That Were Used for NGS Assessment. Samples of Cases with Invasive Mycosis Had Been Assessed by HE, Giemsa, PAS, and Grocott Staining [13], Samples of Cases with Invasive Amebiasis by PAS Staining [7]. Especially in the Case of Filamentous Fungi, No Quantification Had Been Attempted, Because Elements of a Multiply-cut Filament Were Indistinguishable from Single Cuts of Multiple Filaments

\begin{tabular}{|c|c|c|}
\hline Sample & Histological diagnosis & Microscopic confirmation of pathogens in neighboring sections of the materials for NGS assessment \\
\hline 1 & Chromoblastomycosis & Microorganisms seen, no quantification performed \\
\hline 2 & Mucormycosis & Microorganisms seen, no quantification performed \\
\hline 3 & Histoplasmosis & Microorganisms seen, $<10$ pathogens per unit area $(160 \mu \mathrm{m} \times 210 \mu \mathrm{m})$ \\
\hline 4 & Mucormycosis & Microorganisms seen, no quantification performed \\
\hline 5 & Histoplasmosis or cryptococcosis & Microorganisms seen, $<10$ pathogens per unit area $(160 \mu \mathrm{m} \times 210 \mu \mathrm{m})$ \\
\hline 6 & Chromoblastomycosis & Microorganisms seen, no quantification performed \\
\hline 7 & Rhinosporidiosis & Microorganisms seen, no quantification performed \\
\hline 8 & Mycetoma & Microorganisms seen, no quantification performed \\
\hline 9 & Rhinosporidiosis & Microorganisms seen, no quantification performed \\
\hline 10 & Mycetoma & Microorganisms seen, no quantification performed \\
\hline 11 & Histoplasmosis & Microorganisms seen, $<10$ pathogens per unit area $(160 \mu \mathrm{m} \times 210 \mu \mathrm{m})$ \\
\hline 12 & Histoplasmosis & Microorganisms seen, $<10$ pathogens per unit area $(160 \mu \mathrm{m} \times 210 \mu \mathrm{m})$ \\
\hline 13 & Chromoblastomycosis & Microorganisms seen, no quantification performed \\
\hline 14 & Histoplasmosis & Microorganisms seen, $<10$ pathogens per unit area $(160 \mu \mathrm{m} \times 210 \mu \mathrm{m})$ \\
\hline 15 & Coccidioidomycosis & Microorganisms seen, no quantification performed \\
\hline 16 & Coccidioidomycosis & Microorganisms seen, no quantification performed \\
\hline 17 & Mycetoma & Microorganisms seen, no quantification performed \\
\hline 18 & Invasive amebiasis & Microorganisms seen, $>5$ pathogens per unit area $(160 \mu \mathrm{m} \times 210 \mu \mathrm{m})$ \\
\hline 19 & Invasive amebiasis & Negative microscopy in neighboring sections \\
\hline 20 & Invasive amebiasis & Microorganisms seen, $>5$ pathogens per unit area $(160 \mu \mathrm{m} \times 210 \mu \mathrm{m})$ \\
\hline 21 & Invasive amebiasis & Microorganisms seen, $<0.5$ pathogens per unit area $(160 \mu \mathrm{m} \times 210 \mu \mathrm{m})$ \\
\hline 22 & Invasive amebiasis & Negative microscopy in neighboring sections \\
\hline 23 & Invasive amebiasis & Uncertain microscopic result in neighboring sections \\
\hline
\end{tabular}

2015 (ftp://ftp.ncbi.nlm.nih.gov/refseq/release/). The classification was visualized using Krona 2.6 [53].

The analyzed sequence data sets were stored in the database Sequence Read Archive (Sequence Read Archive (SRA) study accession SRP091494). In addition, the data sets can be provided by Bernd Kreikemeyer on request.

\section{Evaluation}

The NGS results were visualized by means of the Krona software [53] and initially analyzed according to the following criteria: total number of reads (single sequence fragments); number and percentage of nonassignable reads in comparison with the NCBI RefSeq database; and finally the percentages of human, protozoan, bacterial, archaean, viral and fungal sequences. Among the fungal sequence reads, the three most frequent fungal species were identified in each sample material.

All samples were also searched for specific sequences that could be assigned by the software Kraken to pathogens that were potentially relevant as causal agents for the 23 study materials and their histologically diagnosed pathologies. In this assessment, disease patterns that are defined by their pathogens, such as E. histolytica-associated amebiasis, histoplasmosis (caused by Histoplasma capsulatum), cryptococcosis (caused by Cryptococcus spp.), and coccidioidomycosis (caused by Coccidioides spp.) were relatively easy to assign. Some of the invasive mycoses studied can be caused by a wide variety of potential pathogens. Because a possible etiologic relevance of $E$ dispar in invasive amebiasis has been discussed repeatedly [54-57], this species was also included in the evaluation.

Potential relevant pathogens for poly-causal infectious diseases [58-61] are summarized in Table 11.

The percentage of pathogen-specific sequence fragments (paired reads) in relation to all reads in the sample was calculated and, if applicable, also in relation to the fungus/bacteria-associated reads. To define the frequency of such verified reads with diagnostic significance as opposed to DNA contamination, i.e. influx from the environment, during sample preparation, 
Table 10 PCR Oligonucleotides Used for the Molecular Characterization of the Samples [7, 13, 62, 63]

\begin{tabular}{cl}
\hline Pan-fungal PCR 1 (variable 18S rRNA gene region) \\
Forward primer RTP_1 & 5'-ATT-GGA-GGG-CAA-GTC-TGG-TG-3' \\
Reverse primer RTP_2 & 5'-CCG-ATC-CCT-AGT-CGG-CAT-AG-3' \\
Probe 1 RTP_p1 & 5'-3FL-TTC-AAC-TAC-gAg-CTT-TTT- \\
& AAC-Tg-3' \\
Probe 2 RTP_p2 & 5'-LC-Red640-AAC-AAC-TTT-AAT-ATA- \\
& CgC-TAT-Tgg A-3'
\end{tabular}

Pan-fungal PCR 2 (variable ITS-2 region of the fungal rRNA operon)

$\begin{array}{ll}\text { Forward primer 5.8S } & \text { 5'-GTG-AAT-CAT-CGA-RTC-TTT-GAA-C- } \\ & \text { 3' }^{\prime} \\ \text { Reverse primer 28S1-rev } & \text { 5'-TAT-GCT-TAA-GTT-CAG-CGG-GTA-3' }\end{array}$

Pan-fungal PCR 3 (variable $28 \mathrm{~S}$ rRNA gene region)

Forward primer 28S-10 5'-GAC-ATG-GGT-TAG-TCG-ATC-CTA-3'

Reverse primer 28S-12-rev 5'-CCT-TAT-CTA-CAT-TRT-TCT-ATCAAC-3'

Pan-fungal PCR 4 (variable ITS-2 region of the fungal rRNA operon)

Forward primer ITS-3

5'-GCA-TCG-ATG-AAG-AAC-GCA-GC-3'

Reverse primer ITS-4

5'-TCC-TCC-GCT-TAT-TGA-TAT-GC-3'

Pan fungal PCR 5 (variable ITS-1 region of the fungal rRNA operon)

Forward primer ITS-1

5'-TCC-GTA-GGT-GAA-CCT-GCG-G-3'

Reverse primer ITS-2

5'-GCT-GCG-TTC-TTC-ATC-GAT-GC-3'

Histoplasma capsulatum PCR (gene encoding the unique fungal 100kDa-like protein)

$\begin{array}{ll}\text { Forward primer } 1 \mathrm{HC} \mathrm{I} & \text { 5'-GCG-TTC-CGA-GCC-TTC-CAC-CTC- } \\ & \text { AAC-3' } \\ \text { Forward primer 2 HC III } & \text { 5'-GAG-ATC-TAG-TCG-CGG-CCA-GGT- } \\ & \text { TCA-3' } \\ \text { Reverse primer } 1 \mathrm{HC} \mathrm{IV} & \text { 5'-AGG-AGA-GAA-CTG-TAT-CGG-TGG- } \\ & \text { CTT-G-3' } \\ \text { Reverse primer } 3 \mathrm{HC} \text { II } & \text { 5'-ATG-TCC-CAT-CGG-GCG-CCG-TGT- } \\ & \text { AGT-3' }\end{array}$

Mucorales PCR (18S rRNA gene)

Forward primer ZM1

5'-ATT-ACC-ATG-AGC-AAA-TCA-GA-3'

Reverse primer 1 ZM3

5'-CAA-TCC-AAG-AAT-TTC-ACC-TCT-

$A G-3^{\prime}$

Reverse primer 2 ZM2

5'-TCC-GTC-AAT-TCC-TTT-AAG-TTT-C$3^{\prime}$

Duplex PCR for Entamoeba histolytica and Entamoeba dispar (fragment of the ribosomal RNA gene located on an episomal plasmid)

Forward primer Ehd-239F

5'-ATT-GTC-GTG-GCA-TCC-TAA-CTC-A$3^{\prime}$

Reverse primer Ehd-88R

5'-GCG-GAC-GGC-TCA-TTA-TAA-CA-3'

Probe 1 histolytica-96T (spe- 5'-JOE-TCA-TTG-AAT-GAA-TTG-GCCcific for E. histolytica) ATT-T-BHQ1-3'

Probe 2 dispar-96 T (specific $\quad$ 5'-Cy5-TTA-CTT-ACA-TAA-ATT-GGCfor E. dispar) CAC-TTT-G-BHQ2-3'

Inhibition control PCR (Phocid herpesvirus 1 (PhHV-1) 1 gB gene)

Forward primer PhHV-267s

5'-GGG-CGA-ATC-ACA-GAT-TGA-ATC$3^{\prime}$

Reverse primer PhHV-337as
Table 10 PCR Oligonucleotides Used for the Molecular Characterization of the Samples $[7,13,62,63]$ (Continued)

\begin{tabular}{cc} 
Probe PhHV-305tq & 5'-Cy55-TTT-TTA-TGT-GTC-CGC-CAC- \\
& CAT-CTG-GAT-C-BBQ-3' \\
Sample quality assessment PCR (human 185 rRNA gene) & Forward primer 18S-f \\
5everse primer 18S-r & 5'-CTC-TTA-GCT-GAG-TGT-CCC-GC-3' \\
& GA-3' \\
Probe 18S-p & 5'-FAM-CCG-GGC-CTC-AGT-TCC- \\
& GCA-GCT-A-TAMRA-CGC-CTG-GAT-ACC- \\
\hline
\end{tabular}

averages of the percentages of the pathogen-specific reads were calculated including all samples. Then, it was established for which individual samples the detected percentages of pathogen-specific reads exceeded the 1st, 2nd, 3rd, and 4th standard deviations above the mean of all examined histologically positive and negative samples (in terms of potential cut-off values). In this context, "negative samples" mean samples with histological results that do not match the respective NGS-based identified pathogen. For these samples with larger than average proportions of specific pathogen sequences, NGS-based diagnosis was compared with histological diagnosis to examine the diagnostic reliability of such standard deviation-based thresholds.

\section{Ethics}

Ethical approval for this retrospective study using residual materials was granted by the Ethics Committee of

Table 11 Genera with Potential Etiological Relevance for Chromoblastomycosis, Mucormycosis, Mycetoma, or Rhinosporidiosis-like Disease

Chromoblastomycosis-associated pathogens:

Achaetomium spp., Alternaria spp., Aureobasidium spp., Bipolaris spp., Botryosphaeria spp., Capronia spp., Chaetomium spp.,

Cladophialophora spp., Cladosporium spp., Cochliobolus spp.,

Curvularia spp., Cyphellophora spp., Davidiella spp., Discosphaerina spp., Exophiala spp., Exserohilum spp., Fonsecaea spp., Graphium spp., Hormonema spp., Hortaea spp., Lasiodiplodia spp., Lewia spp., Nattrassia spp., Ochroconis spp., Phaeacremonium spp., Phialemonium spp., Pleurostomophora spp., Phialophora spp., Pseudallescheria spp., Ramichloridium spp., Rhinocladiella spp., Sarcinomyces spp.,

Scedosporium spp., Scytalidium spp., Setosphaeria spp., Sporothrix spp., and Sydowia spp. [58]

Mucormycosis-associated pathogens:

Absidia spp., Apophysomyces spp., Cokeromyces spp.,

Cunninghamella spp., Mortierella spp., Mucor spp., Rhizomucor spp.,

Rhizopus spp., Saksenaea spp., and Syncephalastrum spp. [59]

Mycetoma-associated pathogens:

Acremonium spp., Aspergillus spp., Fusarium spp., Leptosphaeria spp., Madurella spp., Pseudallescheria spp., and Scedosporium spp. The bacteria-associated actinomycetoma can be caused by species of the genera Actinomadura spp., Nocardia spp., and Streptomyces spp. [60]

Rhinosporidiosis-like disease-associated pathogens:

Lacazia spp., Pythium spp., and Rhinosporidium spp. [61] 
the Medical Association of Hamburg (document number WF-028/13) in line with national and ICH-GCP guidelines. Consent for the anonymous use of the materials was not demanded by the ethics committee. In detail, because the anonymized samples cannot be assigned to a human being, the project did not constitute a research project on humans according to the definitions of $\mathbb{9} 9$ (2) of the Hamburg Medical Association Act for health professions and was also not restricted by $\mathbb{\$} 15$ (1) of the Professional Regulations for physicians in Hamburg, Germany.

\section{Acknowledgments}

Annett Michel and Simone Priesnitz are gratefully acknowledged for excellent technical assistance.

\section{Funding}

The next generation sequencing (NGS) analyses were funded by grant 12 K2S-451315 "Optimizing of microbiological diagnostic pre-analytics for tropical conditions" of the German Ministry of Defense (MoD) awarded to Hagen Frickmann and Ralf Matthias Hagen. The purchase of the Illumina MiSeq system was kindly supported by the EU-EFRE (European Funds for Regional Development) program and funds from the University Medicine Rostock awarded to Bernd Kreikemeyer. The funding body did not have any role in the design of the study, in the collection, analysis, and interpretation of data, or in writing the manuscript.

\section{Availability of data and materials}

The datasets generated and/or analyzed during the current study are available in the database Sequence Read Archive (Sequence Read Archive (SRA) study accession SRP091494). In addition, the data sets can be provided by Bernd Kreikemeyer on request.

\section{Authors' contributions}

$H F, R M H$ and BK were in charge of conception and design of the study. AP, $\mathrm{JN}$ and BK were responsible for the acquisition of the data. HF, CK and ML performed analysis and interpretation of the data. All authors were jointly involved in drafting the manuscript and revising it critically for important intellectual content, gave final approval of the version to be published, participated relevantly in the work to take public responsibility for appropriate portions of the content, and agreed to be accountable for all aspects of the work in ensuring that questions related to the accuracy or integrity of any part of the work are appropriately investigated and resolved.

\section{Ethics approval and consent to participate}

Ethical approval for this retrospective study using residual materials was granted by the Ethics Committee of the Medical Association of Hamburg (document number WF-028/13) in line with national and ICH-GCP guidelines. Consent for the anonymous use of the materials was not demanded by the ethics committee. In detail, because the anonymized samples cannot be assigned to a human being, the project did not constitute a research project on humans according to the definitions of $\S 9$ (2) of the Hamburg Medical Association Act for health professions and was also not restricted by $\S 15$ (1) of the Professional Regulations for physicians in Hamburg, Germany.

\section{Consent for publication}

Not applicable.

\section{Competing interests}

The authors declare that they have no competing interests.

\section{Publisher's Note}

Springer Nature remains neutral with regard to jurisdictional claims in published maps and institutional affiliations.

\section{Author details}

'Department of Microbiology and Hospital Hygiene, Bundeswehr Hospital Hamburg, Bernhard-Nocht Str. 74, 20359 Hamburg, Germany. ${ }^{2}$ Institute for Microbiology, Virology and Hygiene, University Medicine Rostock, Schillingallee 70, 18057 Rostock, Germany. ${ }^{3}$ Department of Bioinformatics, Max-Planck Institute for Heart and Lung Research Bad Nauheim, Parkstraße 1, 61231 Bad Nauheim, Germany. ${ }^{4}$ Department of Preventive Medicine, Bundeswehr Medical Academy, Neuherbergstraße 11, 80937 Munich, Germany. ${ }^{5}$ Swiss Tropical and Public Health Institute, Socinstrasse 57, 4051 Basel, Switzerland. ${ }^{6}$ Faculty of Medicine, University Basel, Socinstrasse 57, 4051 Basel, Switzerland.

Received: 3 January 2018 Accepted: 28 March 2019 Published online: 08 April 2019

\section{References}

1. Mauch $\mathrm{H}$. Einfluss von Lagerung und Transport auf das Überleben von Infektionserregern. Bedeutung für eine schnelle mikrobiologische Diagnostik, die Ökonomie und den Patienten. Mikrobiologe. 2008;18:200-4.

2. Hagen RM, Gauthier YP, Sprague LD, Vidal DR, Zysk G, Finke EJ, et al. Strategies for PCR based detection of Burkholderia pseudomallei DNA in paraffin wax embedded tissues. Mol Pathol. 2002:55:398-400.

3. Quach N, Goodman MF, Shibata D. In vitro mutation artifacts after formalin fixation and error prone translesion synthesis during PCR. BMC Clin Pathol. 2004;:1:-5.

4. Huijsmans CJJ, Damen J, Linden JC, Van Der Savelkoul PHM, Hermans MHA. Comparative analysis of four methods to extract DNA from paraffinembedded tissues: effect on downstream molecular applications. BMC Res Notes. 2010;3:239.

5. Lu K, Ye W, Zhou L, Collins LB, Chen X, Gold A, et al. Structural characterization of formaldehyde-induced cross-links between amino acids and desoxynucleotides and their oligomers. J Am Chem Soc. 2010;132: 3388-99.

6. Dietrich D, Uhl B, Sailer V, Holmes E, Jung M, Meller S, et al. Improved PCR performance using template DNA from formalin-fixed and paraffinembedded tissues by overcoming PCR inhibition. PLoS One. 2013;8:e77771.

7. Frickmann H, Tenner-Racz K, Eggert P, Schwarz NG, Poppert S, Tannich E, et al. Influence of parasite density and sample storage time on the reliability of Entamoeba histolytica-specific PCR from formalin-fixed and paraffinembedded tissues. Diagn Mol Pathol. 2013;22:236-44.

8. Oosterheert JJ, van Loon AM, Schuurman R, Hoepelman Al, Hak E, Thijsen S, et al. Impact of rapid detection of viral and atypical bacterial pathogens by real-time polymerase chain reaction for patients with lower respiratory tract infection. Clin Infect Dis. 2005;41:1438-44.

9. Karger BL, Guttman A. DNA sequencing by capillary electrophoresis. Electrophoresis. 2009;30:S196-202.

10. Reischl U, Drosten C, Geißdörfer W, Göbel U, Hoffmann KS, Mauch H, et al. In: Podbielski A, Herrmann M, Kniehl E, Mauch H, Rüssmann H, editors. MiQ 1. Mikrobiologisch-infektiologische Qualitätsstandards. NukleinsäureAmplifikationstechniken (NAT). 3rd ed. München \& Jena: Urban \& Fischer; 2011. p. 51-3.

11. Habib G, Lancellotti P, Antunes MJ, Bongiorni MG, Casalta JP, Del Zotti F, et al. 2015 ESC guidelines for the management of infective endocarditis: the task force for the Management of Infective Endocarditis of the European Society of Cardiology (ESC). Endorsed by: European Association for CardioThoracic Surgery (EACTS), the European Association of Nuclear Medicine (EANM). Eur Heart J. 2015;36:3075-128.

12. Frickmann H, Dekker D, Schwarz NG, Hahn A, Boahen K, Sarpong N, et al. 165 rRNA gene sequence-based identification of bacteria in automatically incubated blood culture materials from tropical sub-Saharan Africa. PLoS One. 2015;10:e0135923.

13. Frickmann H, Loderstaedt U, Racz P, Tenner-Racz K, Eggert P, Haeupler A, et al. Detection of tropical fungi in formalin-fixed, paraffin-embedded tissue: still an indication for microscopy in times of sequence-based diagnosis? Biomed Res Int. 2015;2015:938721.

14. Bhatt AS, Freeman SS, Herrera AF, Pedamallu CS, Gevers D, Duke F, et al. Sequence-based discovery of Bradyrhizobium enterica in cord colitis syndrome. N Engl J Med. 2013;369:517-28.

15. Loman NJ, Constantinidou C, Christner M, Rohde H, Chan JZ, Quick J, et al. A culture-independent sequence-based metagenomics approach to the 
investigation of an outbreak of Shiga-toxigenic Escherichia coli O104:H4. JAMA. 2013;309:1502-10.

16. Fischer $\mathrm{N}$, Rohde $\mathrm{H}$, Indenbirken $\mathrm{D}$, Günther $\mathrm{T}$, Reumann $\mathrm{K}$, Lütgehetmann M, et al. Rapid metagenomic diagnostics for suspected outbreak of severe pneumonia. Emerg Infect Dis. 2014;20:1072-5.

17. Carrick DM, Mehaffey MG, Sachs MC, Altekruse S, Camalier C, Chuaqui R. Robustness of next generation sequencing in older formalin-fixed, paraffin-embedded tissue. PLoS One. 2015;10:e0127353.

18. Ambulos NP Jr, Schumaker LM, Mathias TJ, White R, Troyer J, Wells D, et al. Next-generation sequencing-based HPV genotyping assay validated in formalin-fixed, paraffin-embedded oropharyngeal and cervical cancer specimens. J Biomol Tech. 2016;27:46-52.

19. Drmanac S, Kita D, Labat I, Hauser B, Schmidt C, Burczak JD, et al. Accurate sequencing by hybridization for DNA diagnostics and individual genomics. Nat Biotechnol. 1998:16:54-8.

20. Ronaghi $M$, Pettersson $B$, Uhlén $M$, Nyrén P. PCR-introduced loop structure as primer in DNA sequencing. Biotechniques. 1998;25:876-8 $880-2,884$

21. Margulies M, Egholm M, Altman WE, Attiya S, Bader JS, Bemben LA. Genome sequencing in microfabricated high-density picolitre reactors. Nature. 2005:437:376-80.

22. Shendure J, Porreca GJ, Reppas NB, Lin X, McCutcheon JP, Rosenbaum AM, et al. Accurate multiplex polony sequencing of an evolved bacterial genome. Science. 2005;309:1728-32.

23. Branton D, Deamer DW, Marziali A, Bayley H, Benner SA, Butler T, et al. The potential and challenges of nanopore sequencing. Nat Biotechnol. 2008;26: 1146-53.

24. Harris TD, Buzby PR, Babcock H, Beer E, Bowers J, Braslavsky I, et al. Single-molecule DNA sequencing of a viral genome. Science. 2008;320: 106-9.

25. Turcatti G, Romieu A, Fedurco M, Tairi AP. A new class of cleavable fluorescent nucleotides: synthesis and optimization as reversible terminators for DNA sequencing by synthesis. Nucleic Acids Res. 2008;36:e25.

26. Hasman H, Saputra D, Sicheritz-Ponten T, Lund O, Svendsen CA, FrimodtMøller N, et al. Rapid whole-genome sequencing for detection and characterization of microorganisms directly from clinical samples. J Clin Microbiol. 2014;52:139-46.

27. Kommedal $\varnothing$, Wilhelmsen MT, Skrede S, Meisal R, Jakovljev A, Gaustad P, et al. Massive parallel sequencing provides new perspectives on bacterial brain abscesses. J Clin Microbiol. 2014:52:1990-7.

28. Wilson MR, Naccache SN, Samayoa E, Biagtan M, Bashir H, Yu G, et al. Actionable diagnosis of neuroleptospirosis by next-generation sequencing. N Engl J Med. 2014;370:2234-44.

29. Fischer $N$, Indenbirken $D$, Meyer $T$, Lütgehetmann $M$, Lellek $H$, Spohn $M$, et al. Evaluation of unbiased next-generation sequencing of RNA (RNA-seq) as a diagnostic method in influenza virus-positive respiratory samples. J Clin Microbiol. 2015;53:2238-50

30. Loman NJ, Misra RV, Dallman TJ, Constantinidou C, Gharbia SE, Wain J, et al. Performance comparison of benchtop high-throughput sequencing platforms. Nat Biotechnol. 2012;30:434-9.

31. Sherry NL, Porter JL, Seemann T, Watkins A, Stinear TP, Howden BP. Outbreak investigation using high-throughput genome sequencing within a diagnostic microbiology laboratory. J Clin Microbiol. 2013;51:1396-401.

32. Varanat M, Maggi RG, Linder KE, Horton S, Breitschwerdt EB. Crosscontamination in the molecular detection of Bartonella from paraffinembedded tissues. Vet Pathol. 2009;46:940-4.

33. Mena M, Lloveras B, Tous S, Bogers J, Maffini F, Gangane N, et al. Development and validation of a protocol for optimizing the use of paraffin blocks in molecular epidemiological studies: the example from the HPVAHEAD study. PLoS One. 2017;12:e0184520.

34. Einsele H, Hebart H, Roller G, Löffler J, Rothenhöfer I, Müller CA, et al. Detection and identification of fungal pathogens in blood by using molecular probes. J Clin Microbiol. 1997;35:1353-60.

35. White PL, Barton R, Guiver M, Linton CJ, Wilson S, Smith M, et al. A consensus on fungal polymerase chain reaction diagnosis? A United Kingdom-lreland evaluation of polymerase chain reaction methods for detection of systemic fungal infections. J Mol Diagn. 2006;8:376-84.

36. Balajee SA, Sigler L, Brandt ME. DNA and the classical way: identification of medically important molds in the 21st century. Med Mycol. 2007;45:475-90.

37. Hata DJ, Buckwalter SP, Pritt BS, Roberts GD, Wengenack NL. Real-time PCR method for detection of zygomycetes. J Clin Microbiol. 2008;46:2353-8.
38. Khot PD, Ko DL, Hackman R, Fredricks DN. Development and optimization of quantitative PCR for the diagnosis of invasive aspergillosis with bronchoalveolar lavage fluid. BMC Infect Dis. 2008:8:73.

39. Hrncirova K, Lengerova M, Kocmanova I, Racil Z, Volfova P, Palousova D, et al. Rapid detection and identification of mucormycetes from culture and tissue samples by use of high-resolution melt analysis. J Clin Microbiol. 2010;48:3392-4.

40. Hammond SP, Bialek R, Milner DA, Petschnigg EM, Baden LR, Marty FM. Molecular methods to improve diagnosis and identification of mucormycosis. J Clin Microbiol. 2011;49:2151-3.

41. Fleischhacker M, Schulz $\mathrm{S}$, Jöhrens $\mathrm{K}$, von Lilienfeld-Toal M, Held T, Fietze $E_{\text {, }}$ et al. Diagnosis of chronic disseminated candidosis from liver biopsies by a novel PCR in patients with haematological malignancies. Clin Microbiol Infect. 2012;18:1010-6.

42. Sangoi AR, Rogers WM, Longacre TA, Montoya JG, Baron EJ, Banaei N. Challenges and pitfalls of morphological identification of fungal infections in histologic and cytologic specimens. A ten-year retrospective review at a single institution. Am J Clin Pathol. 2009:131:364-75.

43. Munoz-Cadavid C, Rudd S, Zaki SR, Patel M, Moser SA, Brandt ME, et al. Improving molecular detection of fungal DNA in formalin-fixed paraffinembedded tissues: comparison of five tissue DNA extraction methods using panfungal PCR. J Clin Microbiol. 2010;48:2147-53.

44. Obersteller $\mathrm{S}$, Neubauer $\mathrm{H}$, Hagen RM, Frickmann $\mathrm{H}$. Comparison of five commercial nucleic acid extraction kits for the PCR-based detection of Burkholderia pseudomallei in formalin-fixed, paraffin-embedded tissues. Eu J Microbiol Immunol (Bd). 2016;6:244-52.

45. de Hoog GS, Nishikaku AS, Fernandez-Zeppenfeldt G, Padín-González C, Burger E, Badali $\mathrm{H}$, et al. Molecular analysis and pathogenicity of the Cladophialophora carrionii complex, with the description of a novel species. Stud Mycol. 2007;58:219-34.

46. Takashima M, Sugita T, Shinoda T, Nakase T. Three new combinations from the Cryptococcus laurentii complex: Cryptococcus aureus, Cryptococcus carnescens and Cryptococcus peneaus. Int I Syst Evol Microbiol. 2003;53(Pt 4): 1187-94.

47. Khawcharoenporn T, Apisarnthanarak A, Mundy LM. Non-neoformans cryptococcal infections: a systematic review. Infection. 2007;35:51-8.

48. Junier P, Kim OS, Hadas O, Imhoff JF, Witzel KP. Evaluation of PCR primer selectivity and phylogenetic specificity by using amplification of 16S rRNA genes from betaproteobacterial ammonia-oxidizing bacteria in environmental samples. Appl Environ Microbiol. 2008;74:5231-6.

49. Köser CU, Fraser L, loannou A, Becq J, Ellington MJ, Holden MT, et al. Rapid single-colony whole-genome sequencing of bacterial pathogens. J Antimicrob Chemother. 2014;69:1275-81.

50. Martin M. Cutadapt removes adapter sequences from high-throughput sequencing reads. EMBnetjournal [SI]. 2011;17:10-2.

51. Bolger AM, Lohse M, Usadel B. Trimmomatic: a flexible trimmer for Illumina sequence data. Bioinformatics. 2014;30:2114-20.

52. Wood DE, Salzberg SL. Kraken: ultrafast metagenomic sequence classification using exact alignments. Genome Biol. 2014;15:R46.

53. Ondov BD, Bergman NH, Phillippy AM. Interactive metagenomic visualization in a web browser. BMC Bioinf. 2011;12:385.

54. Shibayama M, Dolabella SS, Silva EF, Tsutsumi V. A Brazilian species of Entamoeba dispar (ADO) produces amoebic liver abscess in hamsters. Ann Hepatol. 2007:6:117-8.

55. Costa CA, De Brito KN, Gomes MA, Caliari MV. Histopathological and immunohistochemical study of the hepatic lesions experimentally induced by Entamoeba dispar. Eur J Histochem. 2010;54:e39.

56. Costa CA, Fonseca TH, Oliveira FM, Santos JF, Gomes MA, Caliari MV. Influence of inflammation on parasitism and area of experimental amoebic liver abscess: an immunohistochemical and morphometric study. Parasit Vectors. 2011:4:27.

57. Dolabella SS, Serrano-Luna J, Navarro-García F, Cerritos R, Ximénez C, Galván-Moroyoqui JM, et al. Amoebic liver abscess production by Entamoeba dispar. Ann Hepatol. 2012;11:107-17.

58. Sybren De Hoog G, Vitale RG. Bipolaris, Exophiala, Scedosporium, Sporothrix, and other dematiaceous fungi. In: Murray PR, Baron EJ, Jorgensen JH, Landry ML, Pfaller MA, editors. Manual of clinical microbiology. 9th ed. Washington, DC: ASM Press; 2007. p. 1899-900.

59. Richardson MD, Koukila-Kahkola P. Rhizopus, Rhizomucor, Absidia, and other agents of systemic and subcutaneous zygomycoses. In: Murray PR, Baron EJ, 
Jorgensen JH, Landry ML, Pfaller MA, editors. Manual of Clinical Microbiology. 9th ed. Washington, DC: ASM Press; 2007. p. 1840

60. Wieser A, Löscher T, Huber K. Das Mycetom - diagnostische Herausforderung in Zeiten der globalen Migration. Mikrobiologe. 2015;3: 107-12.

61. Mendoza L. Lacazia, Pythium, and Rhinosporidium. In: Murray PR, Baron EJ, Jorgensen JH, Landry ML, Pfaller MA, editors. Manual of Clinical Microbiology. 9th ed. Washington, DC: ASM Press; 2007. p. 1937.

62. Bialek R, Feucht A, Aepinus C, Just-Nübling G, Robertson VJ, Knobloch J, et al. Evaluation of two nested PCR assays for detection of Histoplasma capsulatum DNA in human tissue. J Clin Microbiol. 2002:40:1644-7.

63. Bialek R, Konrad F, Kern J, Aepinus C, Cecenas L, Gonzalez GM, et al. PCR based identification and discrimination of agents of mucormycosis and aspergillosis in paraffin wax embedded tissue. J Clin Pathol. 2005;58:1180-4.

Ready to submit your research? Choose BMC and benefit from:

- fast, convenient online submission

- thorough peer review by experienced researchers in your field

- rapid publication on acceptance

- support for research data, including large and complex data types

- gold Open Access which fosters wider collaboration and increased citations

- maximum visibility for your research: over $100 \mathrm{M}$ website views per year

At BMC, research is always in progress.

Learn more biomedcentral.com/submissions 